\title{
Can You Map Global Financial Stability?
}

\author{
Peter Dattels, Rebecca McCaughrin, \\ Ken Miyajima, and Jaume Puig
}




\title{
IMF Working Paper
}

\author{
MCM
}

\section{Can You Map Global Financial Stability?}

\section{Prepared by Peter Dattels, Rebecca McCaughrin, Ken Miyajima, and Jaume Puig'}

June 2010

\begin{abstract}

\section{This Working Paper should not be reported as representing the views of the IMF.}

The views expressed in this Working Paper are those of the author(s) and do not necessarily represent those of the IMF or IMF policy. Working Papers describe research in progress by the author(s) and are published to elicit comments and to further debate.

The Global Financial Stability Map was developed as a tool to interpret the risks and conditions that impact financial stability in a graphical manner. It complements other existing tools for assessing financial stability, and seeks to overcome some of the drawbacks of earlier approaches. This paper provides the motivation for the tool, a detailed discussion of its construction, including the choice of risk factors and conditions, a description of the underlying indicators, and a discussion on how the final assessment is determined. When applied to past events of financial instability, the Global Financial Stability Map performs reasonably well in signaling risks to stability, as well as in characterizing the depth of crisis episodes.
\end{abstract}

JEL Classification Numbers: E60, G00, H00, N2

Keywords: Early-warning indicator, financial crises, financial stability

Author's E-Mail Address:pdattels@imf.org; rmccaughrin@,imf.org; kmiyajima@imf.org; jpuig@imf.org

\footnotetext{
${ }^{1}$ The authors are grateful to Brian Bell who contributed to earlier iterations of this analysis. Serkan Arslanalp, Jochen Andritzky, John Cady, Martin Cihak, Christoph Duenwald, Dale Gray, Katerina Kalcheva, Philippe Karam, Will Kerry, Ashoka Mody, Andrea Richter-Hume, Liliana Schumacher, Alasdair Scott, and Edouard Vidon provided useful comments. All errors are our own.
} 


\section{Contents}

Page

I. Introduction and Overview ........................................................................4

II. Review of Approaches to Monitoring Financial Stability and Motivation ..................5

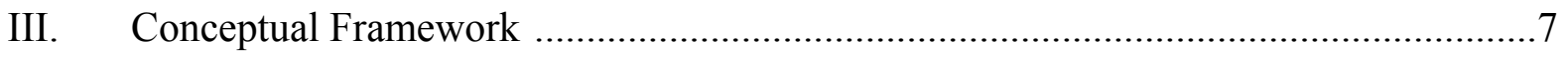

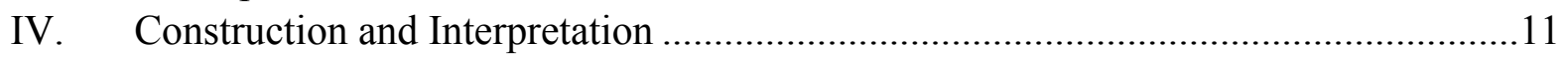

V. Ex-Post Assessment of the Map's Performance ....................................................13

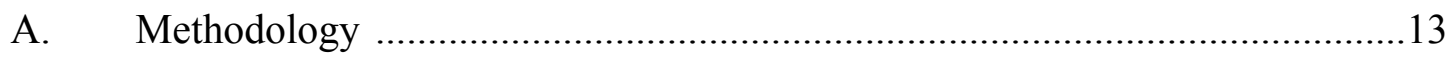

B. Assessment of Crisis Episodes................................................................... 14

Global Credit Crisis

Asian Crisis

Collapse of the U.S. Internet Bubble

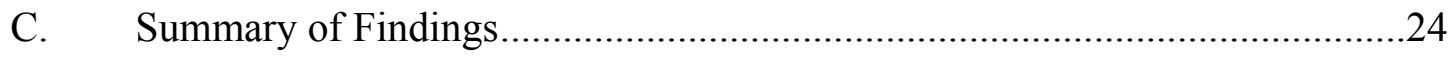

VI. Conclusions and Further Research...............................................................25

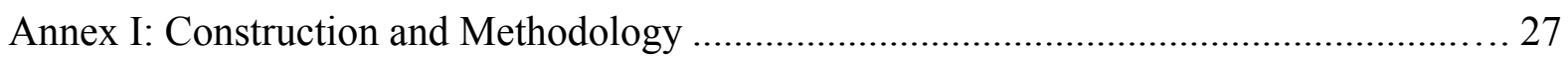

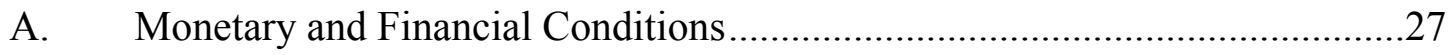

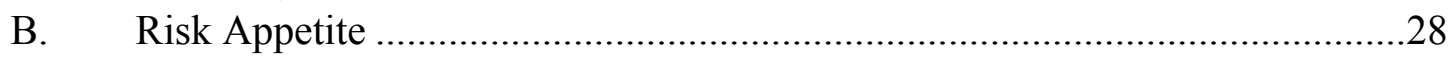

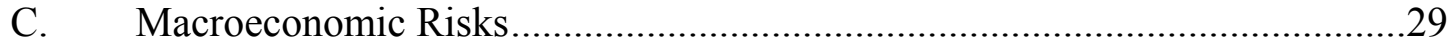

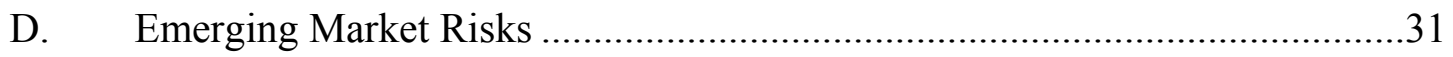

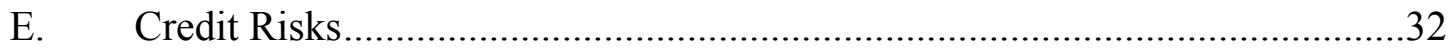

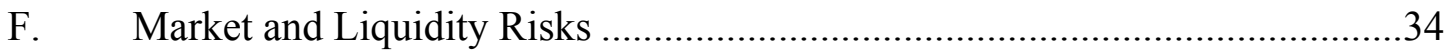

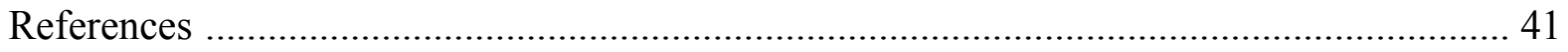

Box I: Indicator-Specific Findings During the 2007-9 Global Credit Crisis .........................16

Tables

1. Performance of Map Indicators in Raising Warning Signals Ahead of Selected Crisis

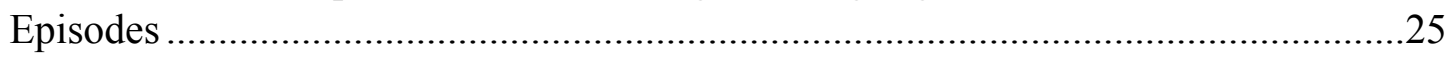

2. Changes in Indicator Composition Since the April 2007 GFSR ...............................36

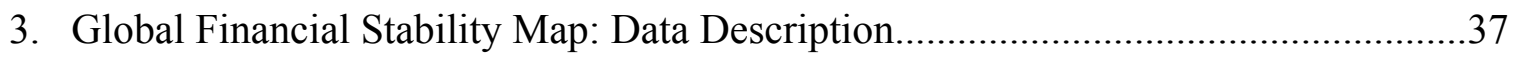

Figures

1. Stylized Graphical Representation of Global Financial Stability ...............................8

2. Global Financial Stability Map Presented in the October 2009 GFSR .......................12

3. Deviations of the Map's Final Positioning from Model Output ................................13

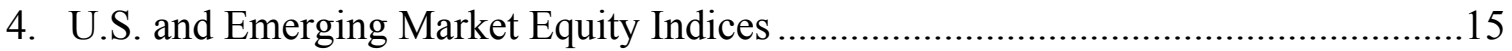

5. Evolution of the Global Financial Stability Map: April 2007-09 GFSRs..................16

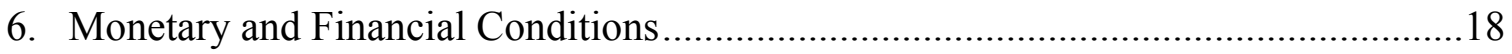

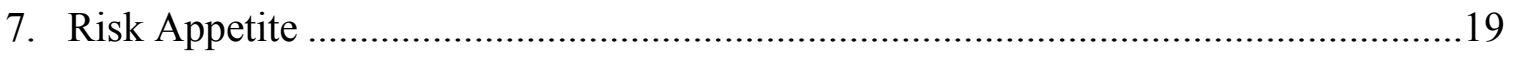




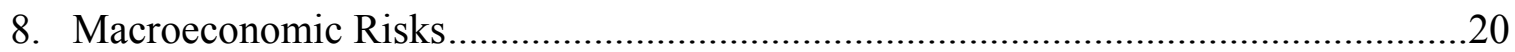

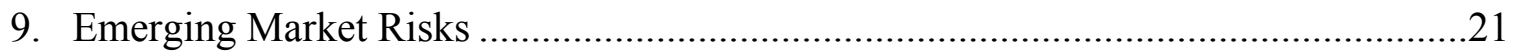

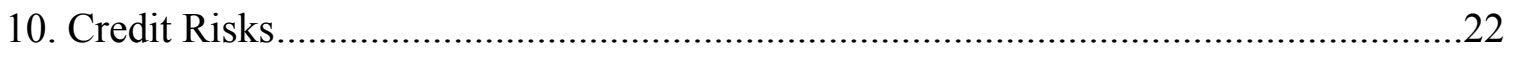

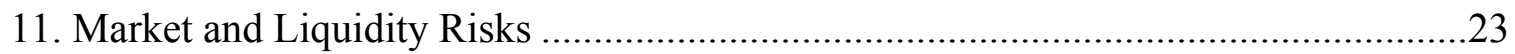

12. Composition of the Map by Type of Indicators in the October 2009 GFSR ….............36 


\section{Introduction and Overview}

\section{The April 2007 Global Financial Stability Report (GFSR) introduced the Global Financial Stability Map (hereafter called "the Map") as a summary tool for} communicating changes in the risks and conditions affecting global financial stability in a graphical manner. The Map was motivated by the increased focus by policymakers on the importance of monitoring financial stability, given the increasing complexity of the underlying factors contributing to instability, the severity of the potential effects of instability on the real economy, and an apparent gap in available surveillance devices. The Map, coupled with other financial surveillance tools, seeks to create a more systematic approach to monitoring the global financial infrastructure to improve the understanding of risks and conditions that affect financial institutions and other intermediaries, and ultimately to warn policymakers and market participants about the risks of inaction.

In this paper, we provide a detailed description of the concepts underlying the Map and its construction. The Map seeks to assess broad risks to financial stability stemming from, and feeding back to, for instance, credit markets, the economy, market and funding liquidity, and leverage. It does not consider certain key sources of stability risks, such as operational risks or the microstructure of asset markets. The paper also assesses the performance of the Map since its first appearance in the April 2007 GFSR, which coincided with the 2007-9 global credit crisis. As well, the paper applies the tool to earlier episodes to help assess its performance during major crisis events, including the Asian crisis and the bursting of the U.S. internet bubble.

\section{The Map's performance has been broadly satisfactory, both as an indicator of mounting risks ahead of, and the depth of stress during, selected crisis events. Ahead of} the crisis episodes considered in the paper, the Map generally signals that risks were very low while conditions were extremely loose, gauged against historical norms, hinting at higher risks to financial stability in the period ahead. During the selected crises, the Map generally captures the worsening of risks and conditions contemporaneously. Judgment and technical adjustment were at times important in setting our final assessment of financial stability, highlighting the importance of qualitative assessments in interpreting the model's outcomes. ${ }^{2}$ Also, certain indicators in the model may send warning signals for an extended period ahead of a crisis episode, indicating imbalances may at times be sustained for a long time before associated risks materialize. There do not appear to be instances where the model signaled type I or II errors - i.e., false positives and negatives - systematically across many indicators. On a cautionary note, the application of this tool to historical episodes of financial instability involves some degree of ambiguity and arbitrariness.

\footnotetext{
${ }^{2}$ Judgment is made based on market intelligence and related surveillance work in order to determine the final positioning in the Map (see section III for a graphical representation of the Map). Technical adjustment is used to account for numerical limitations of the model. For instance, the numerical model underlying the Map is sometimes unable to fully account for extreme events surpassing historical experience.
} 
The Map can be usefully extended to different dimensions. National authorities may apply the framework to country-specific circumstances. The structure may be altered flexibly, by, for instance, introducing additional categories of risks and conditions, or disaggregating certain categories of risks and/or conditions that are more important than others to allow for finer assessment.

Further work will be needed to strengthen the Map's ability to warn of financial stability risks. Additional indicators and techniques will be examined continuously to improve the Map's ability to capture systemic risks. In order to help improve the interpretation of the Map, connectivity needs to be strengthened between different categories of risks and conditions. In our view, judgment will remain essential in assessing risks to financial stability, and should continue to be informed by financial market intelligence. A numerical analysis alone is unlikely to be able to fully characterize crisis episodes, because crises are extreme events, and each crisis is different.

The paper is structured as follows: Section II provides an overview of the existing approaches to assessing financial stability. Section III considers the concept of the Map, while Section IV discusses how the Map is constructed. Section V applies the tool to historical data to help assess the Map's performance prior to, and during episodes of financial instability. Section VI concludes and explores further areas of research. Annex I provides additional details on the Map's indicators as a complement to the main text.

\section{Review of Approaches to Monitoring Financial Stability and Motivation}

There are a number of approaches to assessing financial stability. Earlier approaches tended to focus on stress in individual market segments. Such studies rely on so-called earlywarning indicators to help predict crises in the banking system, and currency, debt, and equity markets, using qualitative (e.g., charting) or econometric approaches. Kaminsky, Lizondo, and Reinhart (1998) were instrumental in developing a systematic quantitative early-warning system to help predict currency crises. IMF staff have also developed various models to help predict currency and balance of payments crises (Berg, Borensztein, and Pattillo, 1999). A more recent example is Aspachs et al (2006), which develops a metric of financial fragility for a range of countries, based primarily on the probability of default of the banking system. The private sector has also developed various early-warning systems, often to monitor risks of sharp movements in currencies or other assets. However, various critical surveys (e.g., Demirgüç-Kunt and Detragiache, 2005) have been rather skeptical of the capacity of early-warning models to predict crises.

Such approaches have a well-defined measure of financial (in)stability, but provide a narrower assessment of risks and are not sufficiently forward-looking. Focusing on a specific segment that is considered to be the main source of vulnerability may be a legitimate simplification for national supervisory authorities. However, the approach is inadequate to assess financial stability on a global basis. In addition, many of the underlying indicators tend to be lagged, or at best coincidental, providing limited insight into future risks. This is especially the case for financial sector assessments, which rely on indicators that tend to lag crises (i.e., non-performing loan ratios or capital adequacy thresholds). Private sector models 
are often designed to help predict crisis events over a short-horizon, typically ranging up to three months.

Another strand of research has developed aggregate indicators intended to encompass a broader definition of financial stability. Financial stability is difficult to define, let alone measure, due to the complex interdependence of different elements within the financial system as well as with the real economy. ${ }^{3}$ Fell and Schinasi (2005), among others, detail the measurement challenges related to assessing financial stability. There are a number of examples of such aggregated indices. Illing and Liu (2003) developed a composite financial stress index for Canada, encompassing the banking sector, currency, equity, and debt markets. Van den End (2006) constructed a financial stability conditions index for the Netherlands and six OECD economies, and compared it to various thresholds of instability. ${ }^{4}$ Hadad et al. (2007) built a financial stability index using Indonesia as a case study, focusing on the local banking system, and equity and bond markets. IMF staff ( $W E O, 2008)$ have also developed financial stress indices. ${ }^{5}$ While such indices are useful summary tools, such an aggregated approach obscures the underlying components of instability, sometimes making it difficult to disentangle the sources of stress.

As part of their efforts to step up financial stability surveillance, many central banks regularly publish financial stability reviews (FSRs) or conduct internal assessments of risks and exposures in the financial system. Cihak (2006), Gadanecz and Jayaram (2009), and Oosterloo and Jong-A-Pin (2007) provide comprehensive surveys of the available financial stability reports and the underlying indicators. While FSRs may contain useful nonpublic data, they tend to be more descriptive in nature (e.g., FSRs generally do not include operational definitions of stability), backward-looking in character (e.g., asset quality indicators), are focused on specific sectors (e.g., usually on the financial sector) and, naturally, the respective domestic economy. Various early-warning indicators are assessed in such studies, but either the analysis is conducted only for internal consumption (as data may be confidential or central banks may be concerned about the consequences of publishing their analysis) or the approach is not systematic.

Other studies assess financial stability based on a broader set of risks, rather than combining all variables into a single indicator. The Bank of England's (BoE) assessment is based on a model of the probability and impact of possible key threats to financial stability, including global parameters (Haldane, Hall and Pezzini, 2007) while also relying on

\footnotetext{
${ }^{3}$ There is no uniformly accepted definition of financial stability. Schinasi (2004) includes a theoretical discussion on the concept. Most studies tend to define financial stability as the antithesis - namely as instability, where system-wide episodes cause the financial system to fail to function and where the institutional underpinnings of the economy are impaired.

${ }^{4}$ The financial stability conditions index is built from real interest rates, real effective exchange rates, housing and stock prices, a so-called solvency buffer, and stock price volatility.

${ }^{5}$ Such indices combine banking sector betas, stock market returns and volatility, sovereign credit spreads, and an indicator of currency market pressure.
} 
qualitative analysis. Like the Map, the BoE approach seeks to focus on a streamlined number of key vulnerabilities (albeit in the U.K. financial system), and takes a systematic approach to assessing the vulnerabilities. ${ }^{6}$ The BoE model seeks to assess a similar set of risks as the Map, including, for instance, credit risk, market risk, funding risk, income generation risk and operational risk. Importantly, the Map presents the underlying risks and conditions, and how they have changed (worsened or improved), but leaves the rest of the GFSR to determine whether they pose a specific threat to global financial stability.

In sum, the drawbacks in earlier studies that motivated the development of the Map include the following: (i) many approaches explicitly focus on only one part of the financial system (generally the banking sector) or on a single dimension or subset of risks (generally credit risks); (ii) other approaches are designed to study selected stress episodes, limiting the predictive power of identifying stress events of a different nature; (iii) the indicators that are selected for stability assessments tend to be low frequency or backward-looking, or at best coincidental, and thus provide limited insight into future risks; and (iv) while clarifying a set of indicators to serve as a threshold is useful to quantifying financial stability, certain approaches risk being overly mechanical.

The Map is intended to complement and build on existing practices as well as on the IMF's broader surveillance and financial stability initiatives. Within the IMF, the financial stability framework includes a number of initiatives designed to assess a country or region's vulnerabilities to potential crisis events. Some of these tools address the vulnerabilities of specific sectors or regions (e.g., through debt sustainability assessments), while others focus on economic vulnerabilities (e.g., via a balance sheet approach). Classical early-warning system models have also historically been the main tool for monitoring financial stability at the IMF. The IMF also collaborates with the Financial Stability Board in an early-warning process to assess systemic risks and key macrofinancial vulnerabilities. ${ }^{7}$

\section{Conceptual Framework}

The Map was designed to assess the risks and conditions that impact financial stability. First introduced in the April 2007 GFSR, the Map is intended to provide a summary, graphical representation of our assessment of financial stability in four risks and two conditions. The Map intends to capture a diverse range of potential sources of instability, contagion among different segments of financial markets, and non-linear interactions among the underlying factors. Figure 1 shows a stylized graphical representation of a Map, where each ray represents a key risk or condition. Dots represent the final assessment of each risk

\footnotetext{
${ }^{6}$ Key vulnerabilities include, for instance, excessively low risk premia, large financial imbalances among major economies, rapid re-leveraging in the corporate sector, high household sector indebtness, rising systemic importance of large and complex financial institutions, and dependence of financial institutions on market infrastructure.

7 The IMF's contribution to this exercise relies on a large number of indicators, including crisis models and other analytical tools, as well as inputs from a broad range of consultations.
} 
and condition category along each ray; closer to the center indicates lower risks or tighter conditions and further from the center represents higher risks or easier conditions.

Figure 1. Stylized Graphical Representation of Global Financial Stability

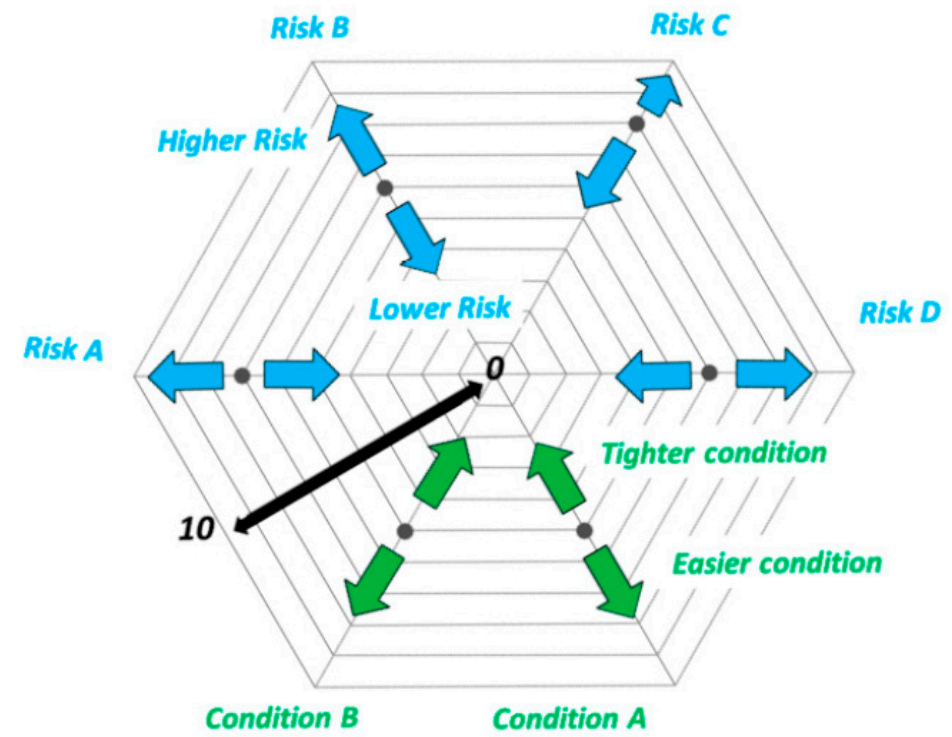

Note: Closer to the center indicates lower risks and tighter conditions.

The philosophy underpinning the Map is that financial stability cannot be distilled into a single indicator, and is better understood by separating the underlying risks and conditions that could give rise to a systemic threat. This is to avoid overlooking specific threats that may be obfuscated by certain risks or conditions offsetting others, and in recognition of the fact that specific threats, triggers, or scenarios can differ over time. The Map is therefore a starting point, not an ending point, for stability analysis. The principles and philosophy of the Map are outlined below.

The Map should be relevant to both financial stability and the Fund's remit in supporting financial stability. This is reflected in the types of risks selected: for instance, one of the rays focuses specifically on risks to emerging markets as an asset class because the Fund's remit includes lending to emerging economies experiencing external financing difficulties. Similarly, macroeconomic risks represent a separate ray in view of the Fund's role in monitoring macroeconomic risks and their linkages to financial stability.

The Map should capture risks over a horizon of the next six to 24 months. Indicators underlying the Map should be of a relatively high frequency in order to register changes on a minimum of a six-monthly basis, which is the frequency of the GFSR publication cycle. Moreover, indicators need to be sufficiently forward-looking, with long-enough history to cover several cycles.

The Map seeks to extract diagnostically-useful information from economic and financial metrics, supplemented by judgment and technical adjustment. There is no single 
canonical model through which the data can be filtered. Although statistical tests are not entirely applicable, Section V attempts to assess the Map's performance during prior crises.

The indicators within each ray of the Map should be sufficient, but limited, in number. Too few indicators would lead to false or erratic readings as they would not give needed breadth, miss sources of the underlying risk, and exaggerate the importance of the indicators used. On the other hand, too many indicators would tend to create an overlap of risk measures, cancel useful information, or over-weight certain indicators. In practice, we have found that 4-8 indicators work best.

Defining the rays requires that risks are separable, distinctly measurable, and relevant to financial stability. The four risks and two conditions included in the Map are highlighted below. A more detailed discussion of the specific types of indicators chosen is included in the Annex. This is more difficult than it sounds, as various indicators might fall into more than one bucket.

Macroeconomic risks affect financial stability through various channels. Three elements are captured here: the global growth outlook that underpins income, the borrower's ability to pay, and overall market perceptions of credit risk. Inflation/deflation risk is a source of financial stability risk as it can destabilize fixedincome markets and impact real debt burdens. Unsustainable fiscal paths increase sovereign risk as rising debt burdens can be a significant source of financial instability.

Emerging market risks represent risks to global financial stability stemming from emerging market asset classes. These focus on underlying fundamentals in emerging markets and vulnerabilities to external shocks. Indicators include models that translate economic, financial and political variables into a valuation of sovereign external credit risk. Underlying indicators of credit and inflation performance capture risks related to financial policies and are leading indicators of future vulnerabilities. Market perceptions of corporate credit risks are also included. Thus, indicators cover policy settings, sovereign risk assessments, and perceptions of corporate sector risk.

Credit risks measure credit stress in household and corporate balance sheets. They also capture risks in both banking and nonbanking systems. Risks in core financial institutions and contagion are assessed using models based on credit derivatives. Pressures in corporate debt markets are captured using delinquency and expected default rates.

Market risks assess the potential for heightened pricing risks that could result in spillovers and/or mark-to-market losses. Liquidity risks measure stress in funding markets as well as liquidity conditions in secondary markets. These indicators highlight the potential for vulnerabilities that arise from excessive leverage - risks that markets might correct abruptly and a liquidity or funding crisis could spill over and impact markets more broadly. 
The Map recognizes the role of monetary policies and financial conditions as well as investor behavior that could create a build-up of risks and imbalances and may trigger a systemic event. For example, as discussed later, prior to the 2007-9 global credit crisis, excessively loose financial conditions, coupled with aggressive investors' appetite for risk, signaled the build-up of leverage and future credit risks. As the crisis deepened, a tightening of conditions and collapse in risk appetite amplified the deterioration of all other risk measures in the Map.

Monetary and financial conditions gauge the stance of monetary policy and the cost and availability of funding. Measures include short-term real interest rates, and estimates of excess liquidity. The willingness and capacity of banks to lend is a key input, as are measures of financial conditions.

Risk appetite gauges the willingness of investors to increase (or shed) risk. Such "animal spirits" can greatly influence spread developments as well as market and liquidity risks. Gauges of risk appetite include survey, market, and fundamentalsbased measures, as well as normalized flows into emerging markets.

More formally, we characterize financial stability $F S$ as a function of six aggregate indicators of risks and conditions $X_{i}$ (for $i=1,2, \ldots, 6$ ), which are, in turn, related to a variety of sub-indicators $a_{j}^{i}$, where $j$ is the number of sub-indicators that varies across $X_{i}$ :

$$
\begin{aligned}
F S & =f\left(X_{1}, X_{2}, \ldots, X_{6}\right) \\
X_{i} & =g\left(a_{1}^{i}, a_{2}^{i}, \ldots, a_{j}^{i}\right)
\end{aligned}
$$

\section{The Map is built from a large number of economic, market, and survey-based} indicators, or $a_{j}^{i} \mathbf{s}$. These indicators are either collected from various external sources or estimated by IMF staff. Some indicators involve modeling of relationships between economic and/or financial variables. The reliability of the indicators is periodically assessed, and adjustments are made by adding or dropping certain indicators so that the Map adequately captures underlying risks and conditions at any given time. ${ }^{8}$ Table 2 in Annex I displays the range of indicators that have been changed since the Map was first introduced in the April 2007 GFSR. We chose indicators that uniquely represent specific risks or conditions, while rejecting those that may be redundant. We opted for indicators with a higher frequency and longer time series, relying on survey-based, macroeconomic, supervisory, and credit ratings data when market-based data are unavailable or deficient (e.g., where illiquidity, seasonality, or other factors impede interpretation), while endeavoring to maintain a representative geographical coverage. We also aimed to balance the mix of price and quantity measures (see Figure 12 in Annex I).

\footnotetext{
${ }^{8}$ When a sub-indicator is added (or dropped) in one GFSR, we do not adjust the positioning of the aggregate risk or condition in previous Maps.
} 


\section{Construction and Interpretation}

Each of the Map's six rays is comprised of equally-weighted sub-components. Weights change as the total number of sub-indicators changes due to additions or deletions. We chose not to attach specific weights to each sub-component, as those weights would likely change over time, depending on the specific threat to financial stability. For instance, capturing a financial crisis that originated in the sovereign debt space would require giving relatively greater weighting to sovereign risk components. Instead, we rely on judgment based on market intelligence to allow for some subjective weighting of indicators. Some overlap among the various sub-components and among categories of risks and conditions is inevitable, especially as indicators feed into risk assessments in different ways. For instance, corporate credit spreads are embedded in financial condition indices that are used to gauge monetary and financial conditions, but are also used to assess credit risks. Overlap across certain components may result in unintentional over-representation of certain subcomponents. (See Table 3 in Annex I for details on specific sub-components.)

Current conditions and risks are gauged against their respective historical norms. Assessments of the contemporaneous values of the indicators are made relative to their own history in terms of percentile rankings. To construct the Map, we first determine the percentile rank of the current level of each sub-indicator relative to its history to guide our assessment of current risks and conditions, relative both to immediately preceding GFSRs and over a longer horizon. Where possible, we have therefore favored indicators with a reasonable history. ${ }^{9}$ Moving averages are often used for higher frequency data to extract the trend and identify inflection points.

The final assessment is made on a scale of 0 to 10, where a higher ranking signifies higher risks, easier monetary and financial conditions, and higher risk appetite. Each sub-indicator's ranking is set relative to its own history, and notch 5 should broadly correspond to the long-term average. ${ }^{10}$ With regard to conditions, this level may, but does not necessarily, represent a 'neutral' level. Figure 2 provides a summary schematic of the risks and underlying conditions underpinning the Map as displayed in the October 2009 GFSR.

\footnotetext{
${ }^{9}$ Lack of history poses some limitations. The length of historical data dictates the number of economic/financial cycles. These vary across different indicators.

${ }^{10}$ The historical average may deviate from notch 5 because we do not rebase notch 5 to the new average of the sub-components even following events that surpass historical experience. This is done in order to help maintain comparability to earlier GFSRs.
} 
Figure 2. Global Financial Stability Map Presented in the October 2009 GFSR

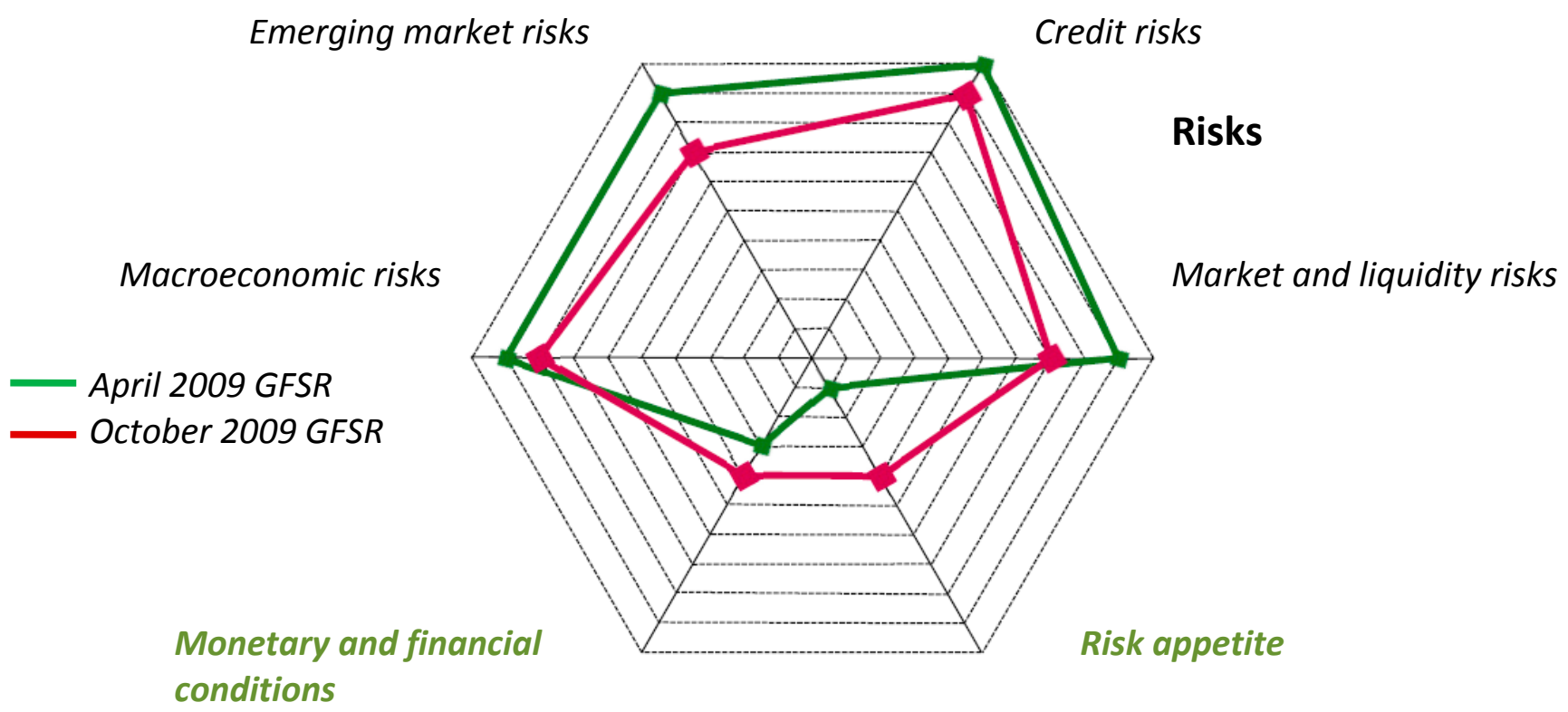

\section{Conditions}

Source: IMF staff estimates.

Note: Closer to the center signifies less risk, tighter monetary and financial conditions, or reduced risk appetite.

The final choice of positioning on the Map represents the best judgment of IMF staff. Judgment is often used to attach greater importance to a particular set of indicators based on risks considered to be most relevant at a given time, based on market intelligence and staff's own assessment. Judgment is also used to account for linkages between different rays. Technical adjustment is introduced to adjust the results of the numerical model underlying the Map, particularly when events that surpass historical experience raise (lower) some associated risk or condition to the highest (lowest) level. ${ }^{11}$ In all cases, we elaborate our assessment in the main text of the GFSR, while highlighting that the relevant risk or condition is at extreme levels by historical standards. Figure 3 shows how judgment and technical adjustment altered the final positioning from the model's results. This figure remains suggestive for reasons we discuss later.

\footnotetext{
${ }^{11}$ Events surpassing historical episodes necessarily place the Map at the boundary, making it difficult to assess subsequent deterioration or improvement. For instance, the 2007-9 global credit crisis led to a significant deterioration in credit risks, pushing credit spreads to unprecedented levels. A further widening in credit spreads thus did not alter the percentile ranking of the associated sub-indicator. During such episodes, technical adjustment is made by changing the percentile ranking of the associated sub-indicator by a larger extent than indicated by the model.
} 


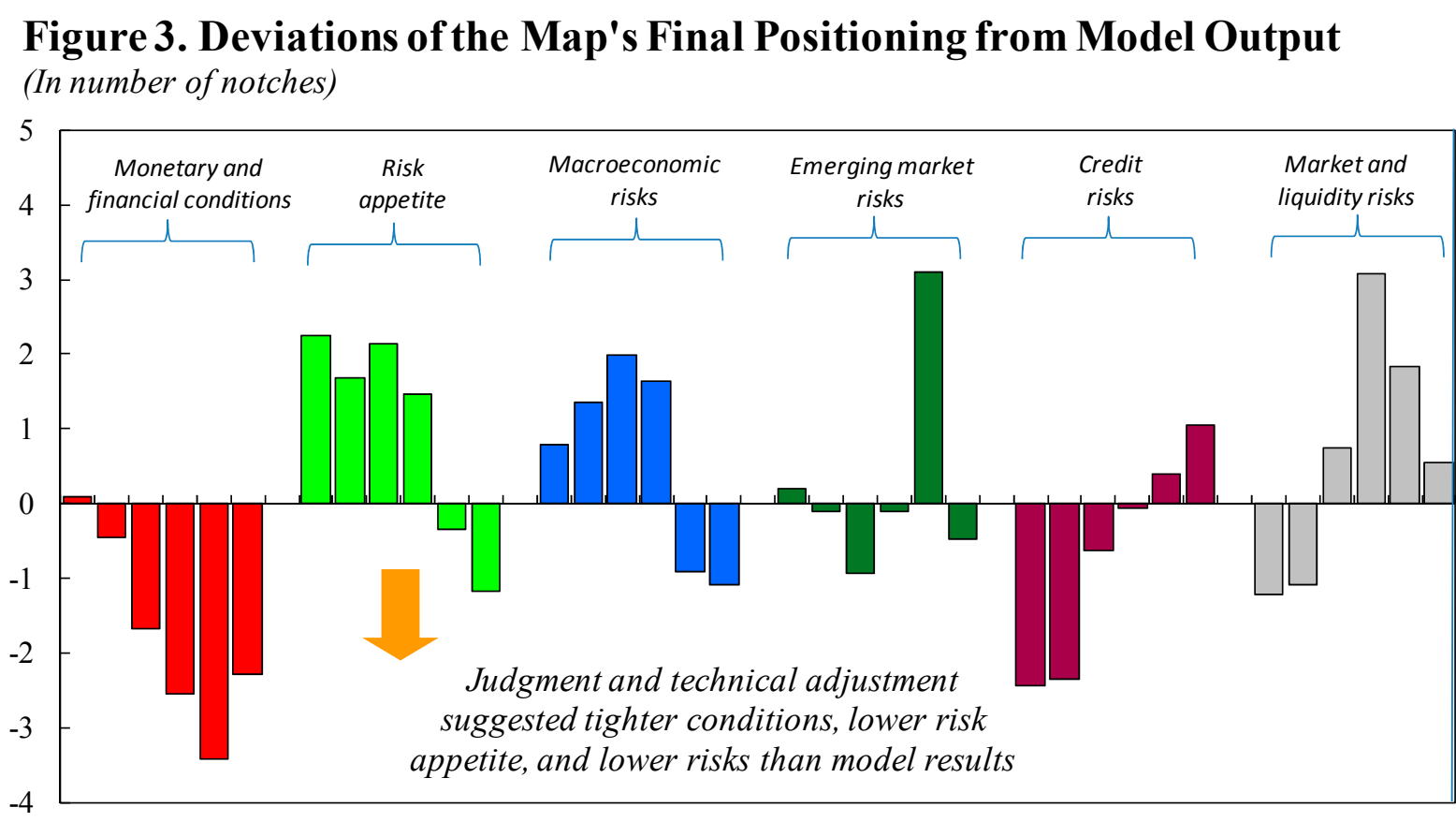

Source: IMF staffestimates.

Note: Showing for six GFSRs, from the April 2007 to October 2009 GFSR. For instance, the blue bar representing macroeconomic risks in the October 2009 GFSR is around-1, indicating that the risk category's final positioning in the Map was one notch lower (less risk) than what the model suggested.

\section{Ex-Post Assessment of the Map's Performance}

\section{A. Methodology}

To assess how the Map performed, we constructed a "historical" Map by extrapolating backward the latest set of underlying sub-indicators. We constructed the model's results with past observations for the indicators used in the October 2009 GFSR. For each indicator, we constructed bands representing one standard deviation above and below the historical average. Indicators that fell outside of these thresholds six months ahead of a crisis episode indicating very low risks and loose conditions are interpreted as signs that risks to financial stability will likely increase in the near term. ${ }^{12}$ However, indicators may produce warning signals well ahead of a crisis episode as imbalances can persist for a considerable time. Indicators that fell outside of the thresholds during a crisis episode are considered to represent a high level of stress stemming from the crisis. Our interpretation is indicatordependent, as we elaborate later.

Two sets of historical Maps were constructed to account for differing data availability. The first set of indicators has a shorter history, and is comprised of all sub-indicators

\footnotetext{
${ }^{12}$ Each six month period was set to be broadly consistent with the past publication schedule of the GFSR.
} 
presented in the October 2009 GFSR $\cdot{ }^{13}$ Since some indicators have relatively limited history, we constructed a second set of indicators using a smaller range of sub-indicators but which have a longer history. In doing so, we sought to strike a balance between the benefit of a longer time series and the constraint of reduced information content.

Given the degree of ambiguity and arbitrariness of this exercise, the results should be viewed as merely illustrative. While the three crisis events selected in this section are not controversial, the choice of the start date of each event is admittedly somewhat arbitrary. Moreover, defining a crisis episode signal by a one standard deviation threshold is also arbitrary, and may be misleading where indicators lack a sufficiently long history to capture several economic cycles. ${ }^{14}$ In addition, we mechanically extended backwards the set of subindicators presented in the October 2009 GFSR, which is different from that used in most of the earlier GFSRs due to changes in the composition of indicators to improve the Map.

\section{B. Assessment of Crisis Episodes}

First, we gauge the Map's performance during the 2007-9 global credit crisis. The crisis unfolded shortly after the Map was introduced in the April 2007 GFSR. We evaluate both (i) the outcomes of a mechanical interpretation of the underlying sub-components and (ii) the extent to which judgment and technical adjustment contributed to the final positioning in the Map. Then, we apply the same quantitative tool to historical data for other selected crisis events, but without further interpreting the outcome using judgment and technical adjustment. Due to data constraints, we restrict our analysis to major crisis events with a global reach from the late-1990s and onwards - including the 1997 Asian crisis and the 2000 U.S. stock market crash, among other candidates..$^{15}$ The start date of each crisis event was determined by stock market performance (Figure 4). Indeed, wealth destruction via a sharp and sustained sell-off in stock markets and other financial markets have an important negative balance sheet effect, amplifying the threats to financial stability.

\footnotetext{
${ }^{13}$ Some sub-indicators were not included.

${ }^{14}$ The mean of the aggregate indices of four risks and two conditions in percentile ranking terms is not necessarily equal to notch 5 , in part because the dynamics of the underlying components may counterbalance each other. Similarly, the aggregate indices do not necessarily extend from notch 0 to 10 during the period we chose for our exercise.

${ }^{15}$ We excluded Russia's default and the collapse of Long-Term Capital Management from our analysis since the close proximity in timing to the Asian crisis made it difficult to disentangle the differing impacts.
} 


\section{Figure 4. U.S. and Emerging Market Equity Indices}

(January 1996=100, log scale)

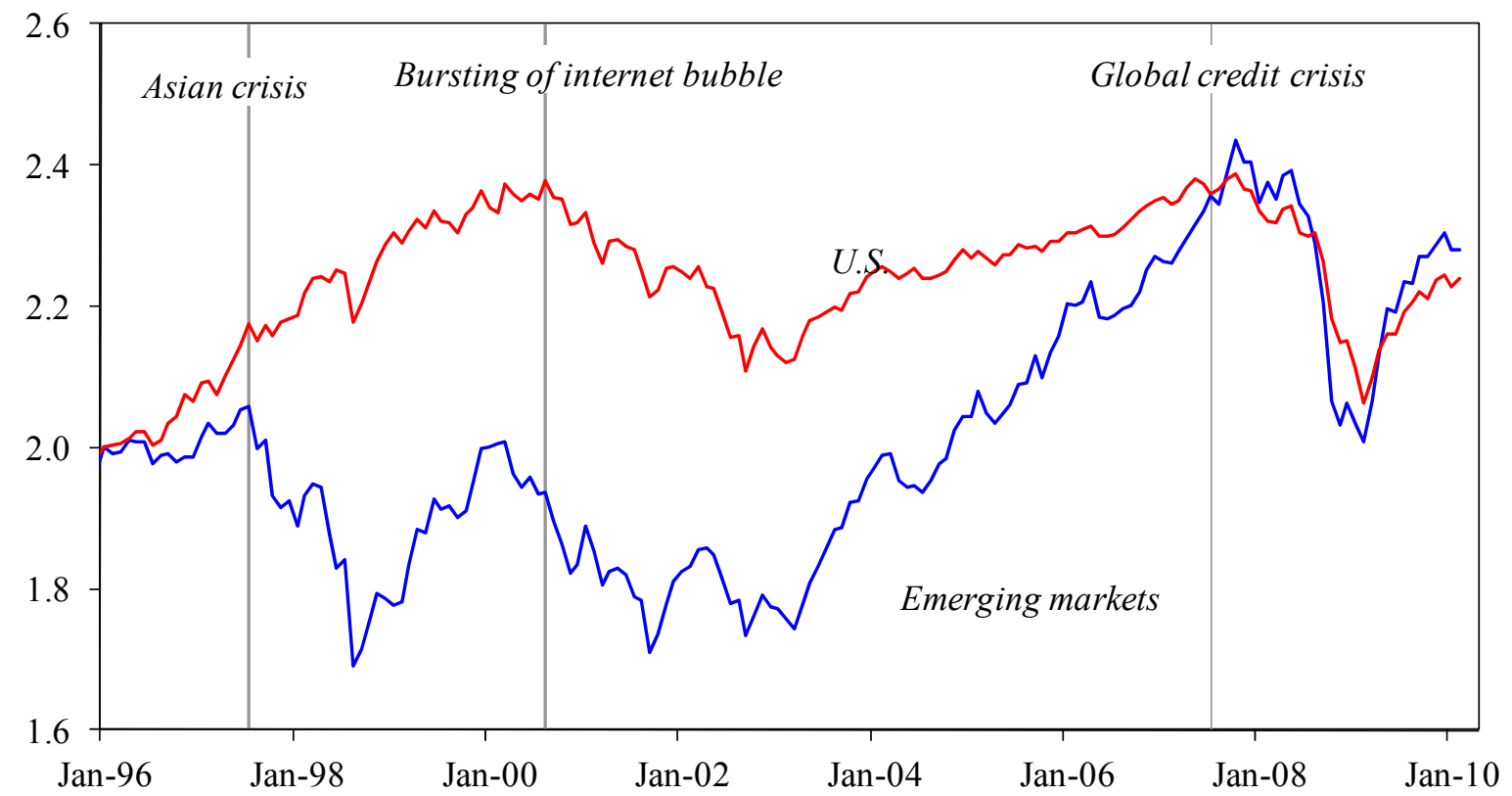

Sources: Bloomberg and IMF staff estimates.

\section{Global Credit Crisis ${ }^{16}$}

Broad developments during the global credit crisis were well-tracked and were to some extent forecasted by the Map. (See Box 1 for an interpretation and Figures 6-11) As highlighted in Figure 5, the Map indicated our principle concern about financial stability in the April 2007 GFSR - namely that a long period of benign financial and macroeconomic conditions had led investors into a prolonged "search for yield," reflected in high levels of risk appetite and an overly benign perception of credit risk. Rising levels of leverage and correlations across markets were also indicative of market risks. As the initial stage of the global credit crisis started to unfold, the indicators that had warned about the accumulation of risks started to signal a realization of risks. By the next GFSR, in October 2007, the Map flagged an increase in credit risks, brought on by a decline in U.S. housing prices and a deterioration in housing markets. The Map tracked the crisis well as deleveraging intensified and liquidity risks increased, denoted by the rise in market and liquidity risks. The collapse of Lehman Brothers in September 2008 and continued pressure on U.S. housing prices led to a sharp rise in credit risks at the core of the financial system, which threatened to spill over to the real economy and emerging markets. The Map signaled a deterioration in emerging market risks with a lag, only around the October 2008 GFSR, consistent with the fact that the crisis originated in mature markets only belatedly spread to emerging markets.

\footnotetext{
${ }^{16}$ July 2007 marked the start date of the crisis.
} 


\title{
Figure 5. Evolution of the Global Financial Stability Map: April 2007-09 GFSRs
}

\author{
Emerging market risks Credit risks
}

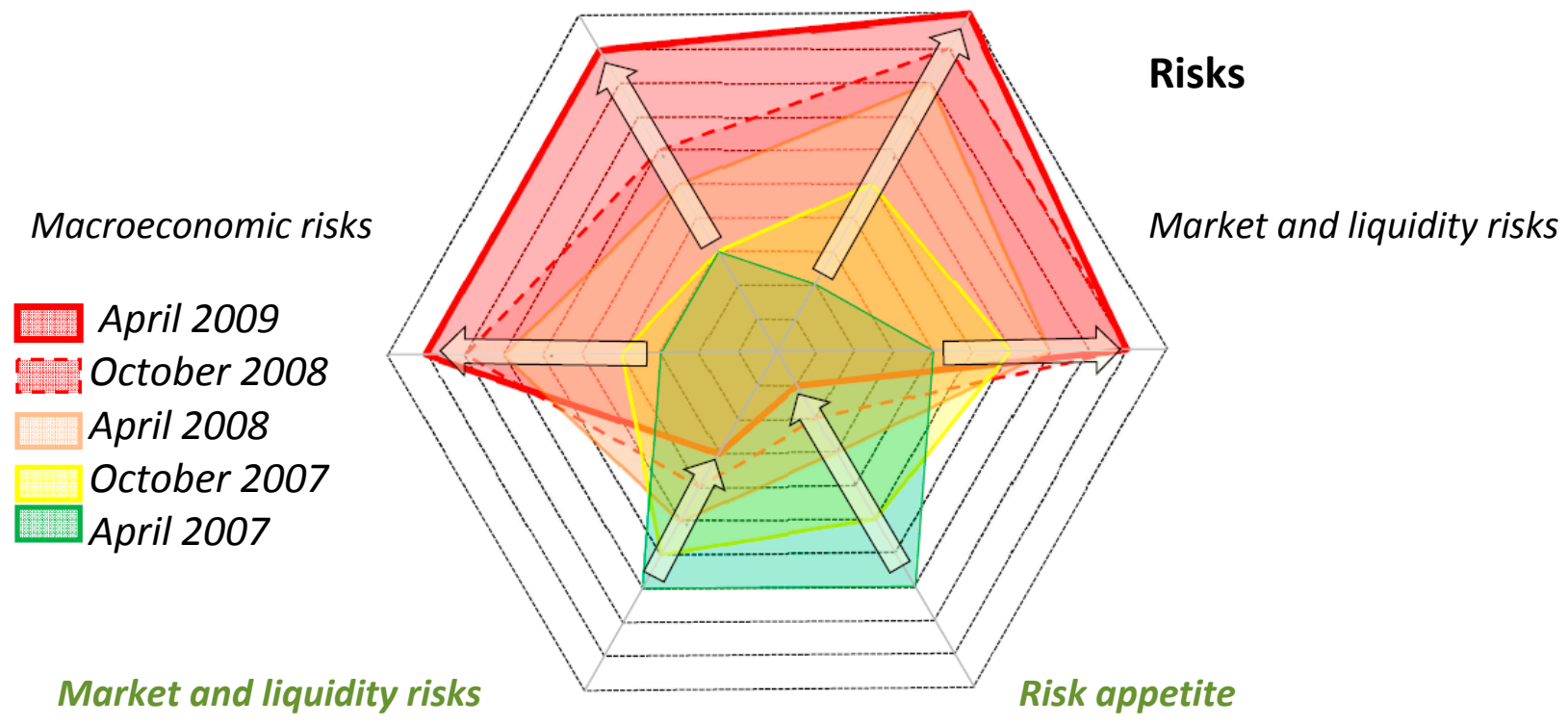

\section{Conditions}

Source: IMF staff estimates.

Note: Closer to the center signifies less risk, tighter monetary and financial conditions, or reduced risk appetite.

\section{Box 1. Indicator-Specific Findings During the 2007-9 Global Credit Crisis}

Monetary and Financial Conditions: The Map signaled excessively easy conditions from 2003 to 2006, suggesting the potential for a build-up of large imbalances ahead of the crisis. Moreover, high levels of risk appetite reinforced this signal. Partly reflecting the nature of the crisis, starting from worries in a sub-segment of credit, there was a long period in the run-up to the crisis before monetary and financial indicators signaled rising risks. In addition, the model did not suggest much tightening until very late in the crisis, as the underlying subindicators did not fully reflect the impact of bank deleveraging. ${ }^{17}$ Overall, the indicator's performance was mixed as an early-warning indicator, but it captured the depth of the crisis once technical adjustment was incorporated to account for consecutive extreme outturns exceeding historical standards.

\footnotetext{
${ }^{17}$ Judgment and technical adjustment were sometimes required to complement methodological constraints related to the construction of the Map. Specifically, the measure of funding quantity (i.e., lending conditions) reached a borderline value at an earlier stage of the global financial crisis. The sub-indicator's percentile ranking could not reflect a further tightening in lending conditions; as such the final overall positioning of monetary and financial conditions in the Map was adjusted.
} 
Risk Appetite: This set of indicators captured the levels of risk appetite in the run-up to the crisis. Indicators pointed to a sharp contraction in risk appetite from very high levels ahead of the crisis, although our assessment was initially driven by judgment and technical adjustment (in part due to fast-moving events and the lag in availability in some survey-based indicators).

Macroeconomic Risks: Indicators signaled excessively low perceptions of risks at the onset of the crisis, and captured deteriorating conditions throughout the crisis as well, with judgment accounting minimally. Leading indicators and the WEO's risk assessment gave a forward-looking assessment of evolving macroeconomic risks.

Emerging Market Risks: These indicators suggested very low perceptions of risks in 200507, and a realization of risks only in late-2008 following the collapse of Lehman Brothers. The assessment of risks reached very high levels in the April 2009 GFSR, partly incorporating judgment to account for the likely adverse impact of unfavorable external financing conditions. ${ }^{18}$ This reflected the fact that the crisis originated in mature markets and the relatively resilient position of emerging markets was only threatened once the financial crisis spread to cross-border funding channels and the real economy.

Credit Risks: Perception of risks increased from very low levels prior to the global credit crisis, signaling rising risks of a credit bubble and strains at the core of the financial system.

Market and Liquidity Risks: This set of indicators tracked the rise in risks to financial stability throughout the crisis period, reaching its highest level after the collapse of Lehman Brothers. While this indicator more precisely captured the depth of the crisis, some of the sub-indicators pointed to increased excessive risk-taking ahead of the crisis in mid-2007 as well.

\footnotetext{
${ }^{18}$ A sub-indicator representing projected private capital inflows to emerging markets was introduced in the April 2009 GFSR to reflect a retrenchment in cross-border bank flows to emerging markets, but was excluded from the Map in the October 2009 GFSR.
} 


\section{Figure 6. Monetary and Financial Conditions}

(Ranking 0-10)

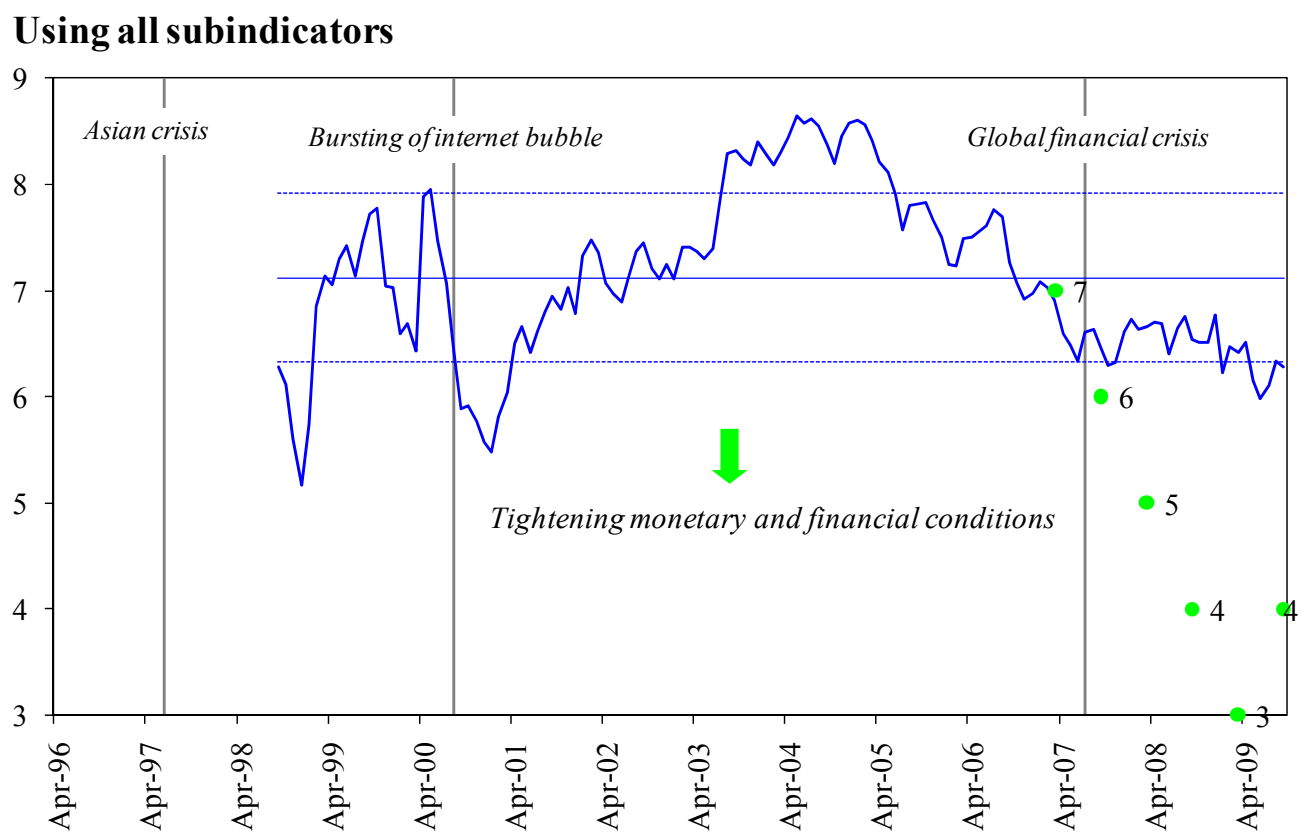

\section{Using subindicators with longer history}

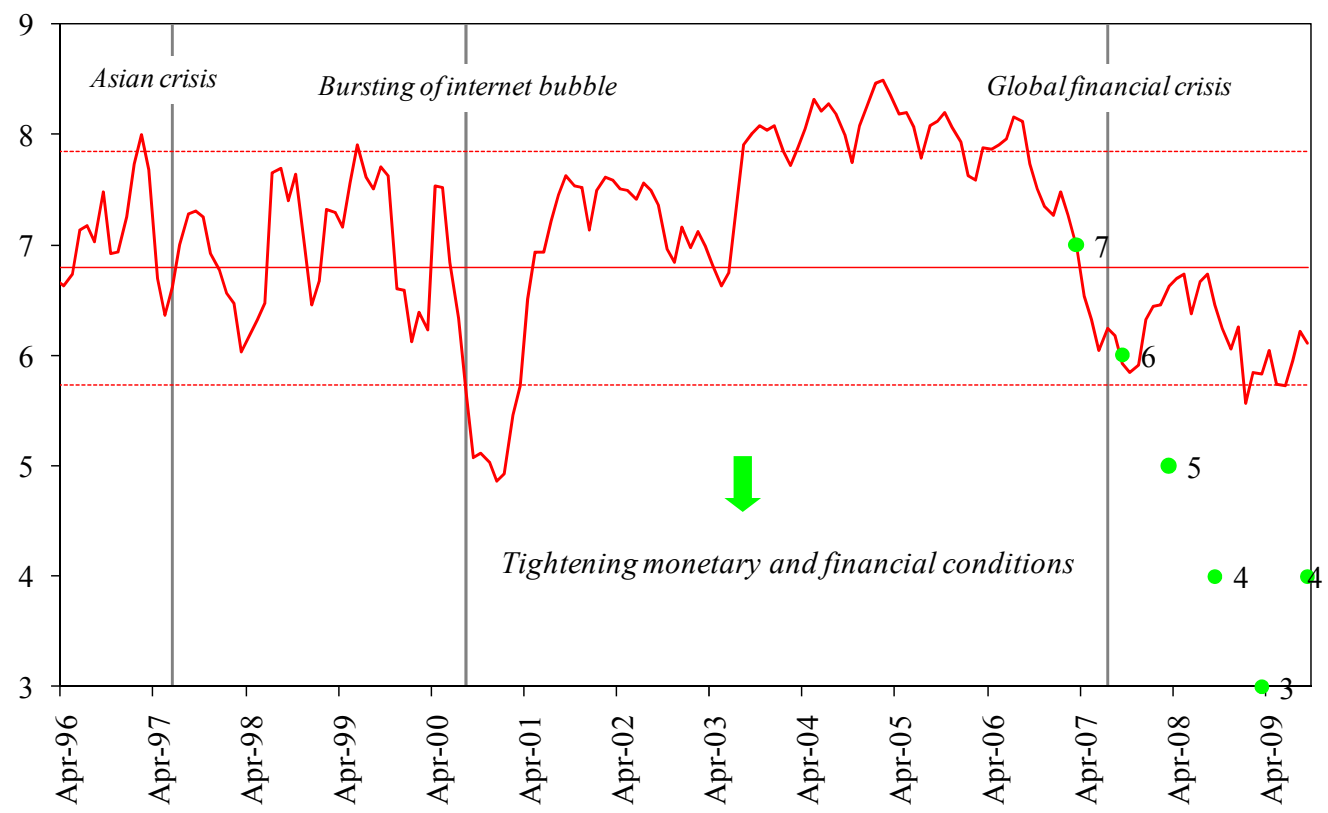

Sources: Bloomberg, Goldman Sachs, central bank lending surveys, Federal Reserve Board, and IMF staff estimates.

Note: The solid lines are the aggregate indices using either a subset of sub-indicators (red) or all subindicators (blue). The dots show the positioning published in past GFSRs (April 2007-October 2009). The solid and broken straight lines indicate the period average and $+/-1$ standard deviation bands. 
Figure 7. Risk Appetite

(Ranking 0-10)

\section{Using all subindicators}

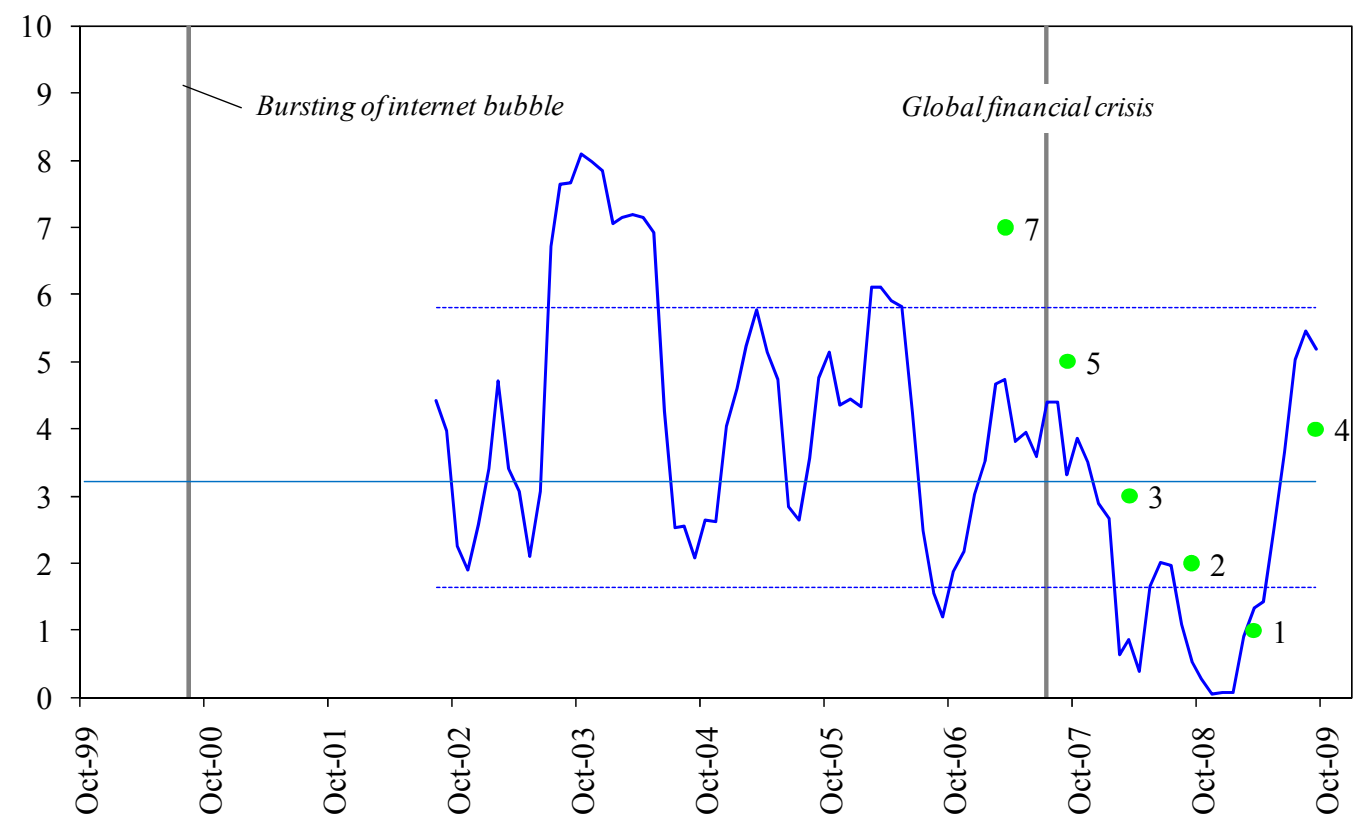

Using subindicators with longer history

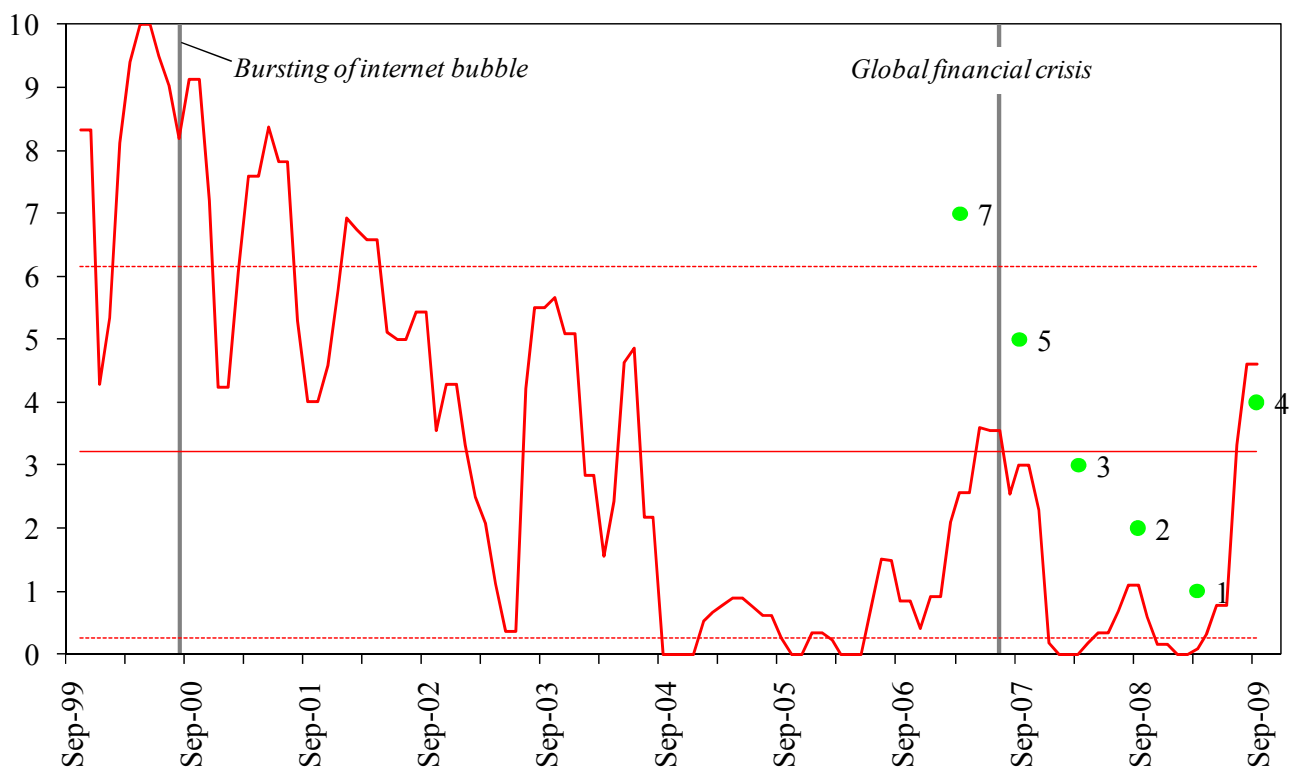

Sources: Emerging Portfolio Fund Research, Merrill Lynch, State Street Global Markets, and IMF staff estimates.

Note: The solid lines are the aggregate indices using either a subset of sub-indicators (red) or all subindicators (blue). The dots show the positioning published in past GFSRs (April 2007-October 2009). The solid and broken straight lines indicate the period average and $+/-1$ standard deviation bands. 
Figure 8. Macroeconomic Risks

(Ranking 0-10)

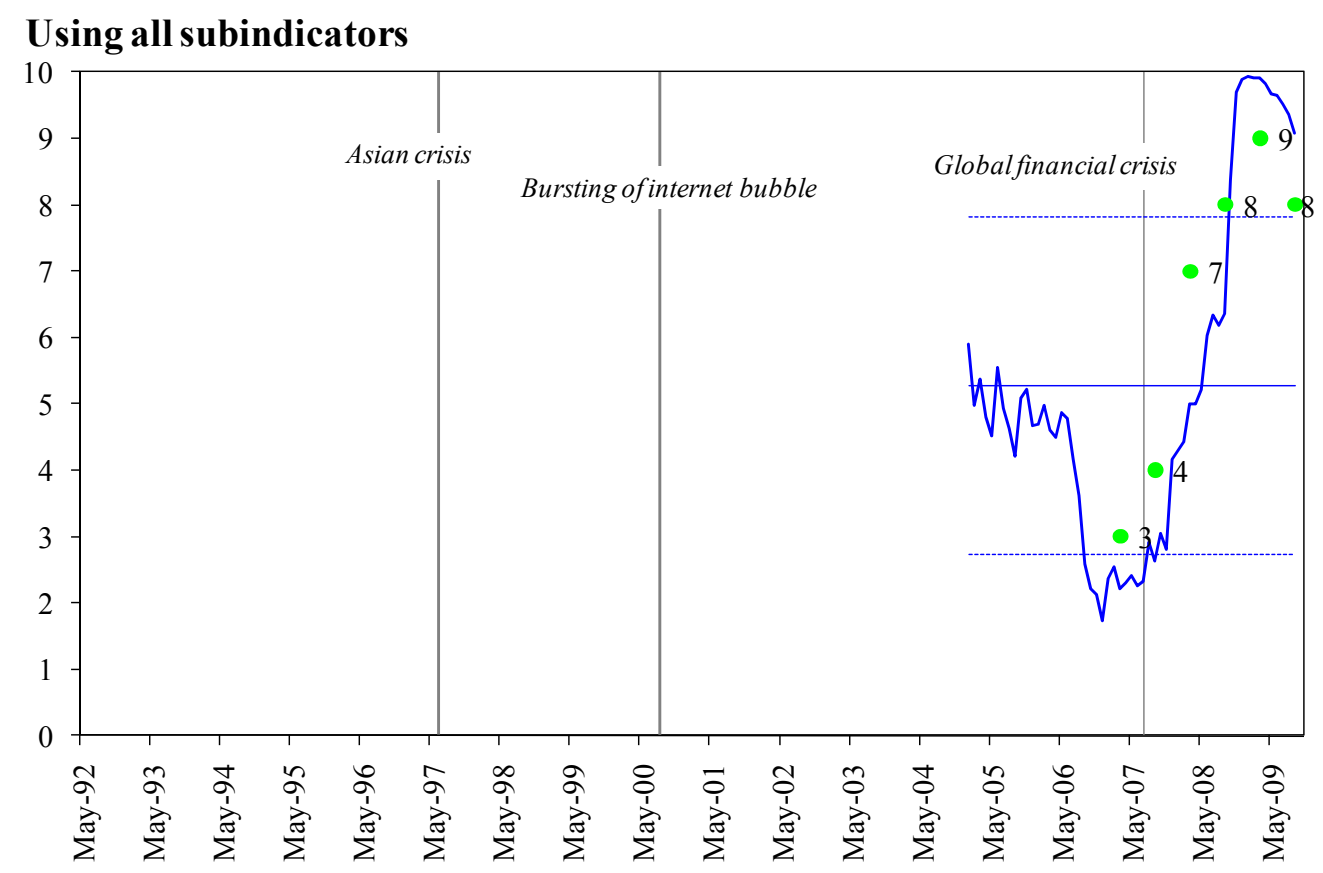

\section{Using subindicators with longer history}

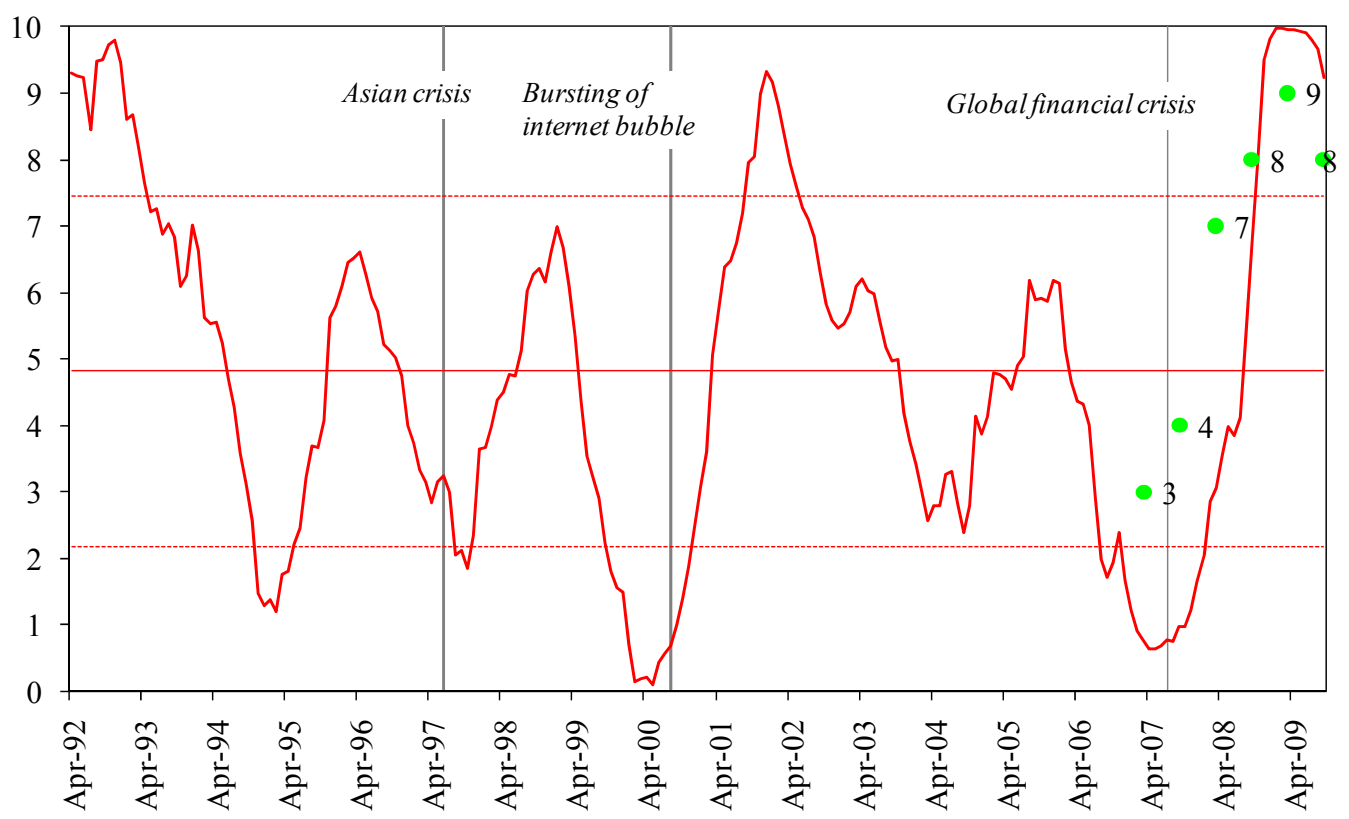

Sources: The Baltic Exchange, Barclays Capital, Bloomberg, DataStream, OECD, and IMF staff estimates.

Note: The solid lines are the aggregate indices using either a subset of sub-indicators (red) or all subindicators (blue). The dots show the positioning published in past GFSRs (April 2007-October 2009). The solid and broken straight lines indicate the period average and $+/-1$ standard deviation bands. 
Figure 9. Emerging Market Risks

(Ranking 0-10)

\section{Using all subindicators}

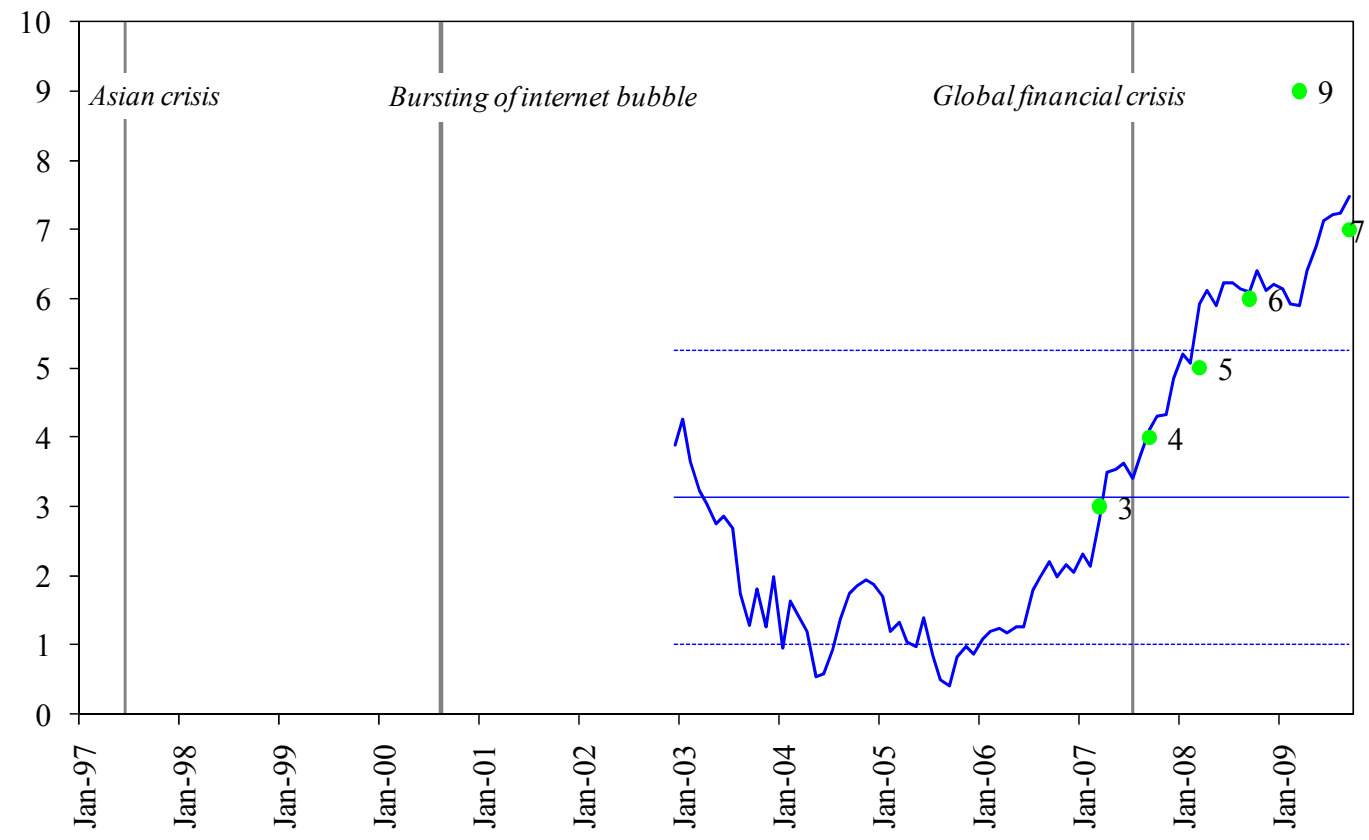

Using subindicators with longer history

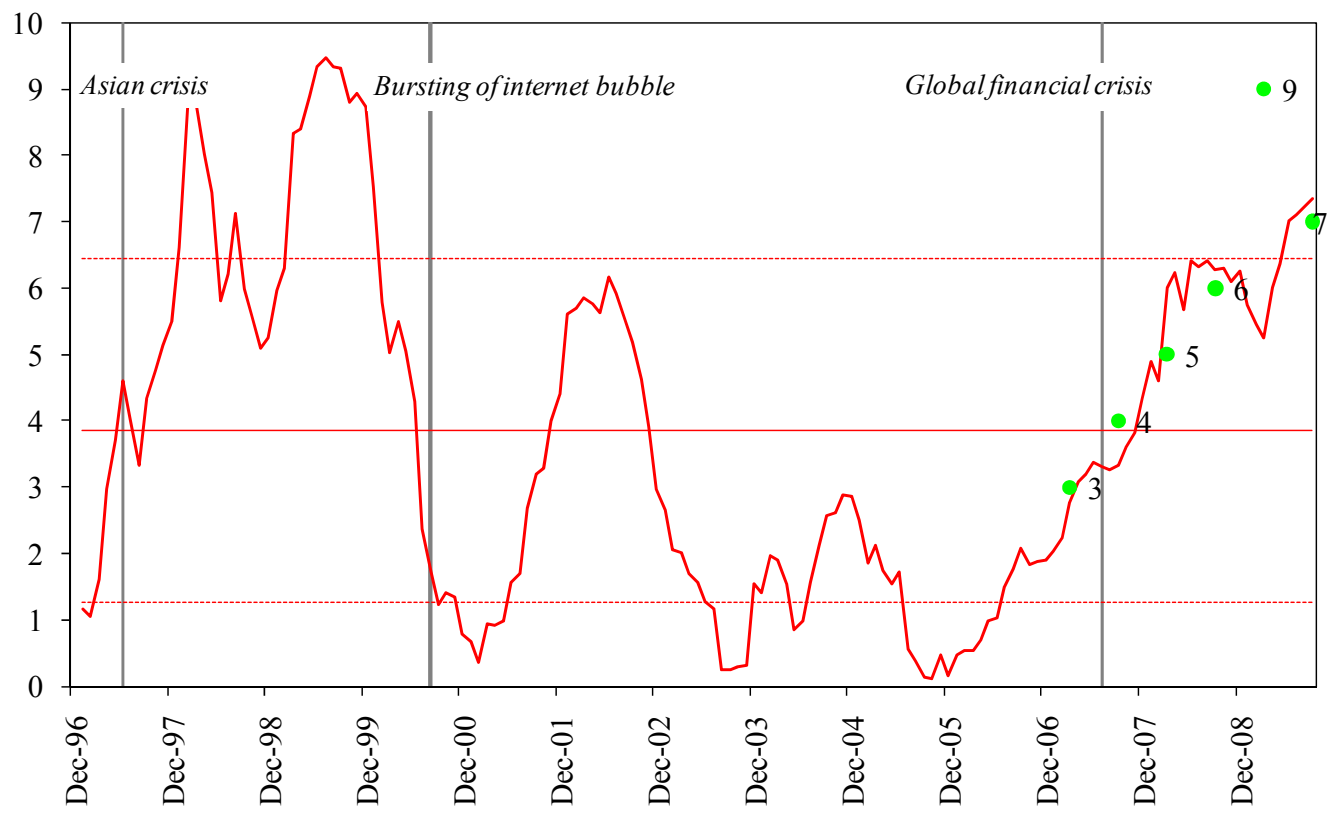

Sources: Bloomberg, IMF International Financial Statistics and World Economic Outlook databases, JPMorgan \& Chase, the PRS Group, and IMF staff estimates.

Note: The solid lines are the aggregate indices using either a subset of sub-indicators (red) or all subindicators (blue). The dots show the positioning published in past GFSRs (April 2007-October 2009). The solid and broken straight lines indicate the period average and $+/-1$ standard deviation bands. 
Figure 10. Credit Risks

(Ranking 0-10)

\section{Using all subindicators}

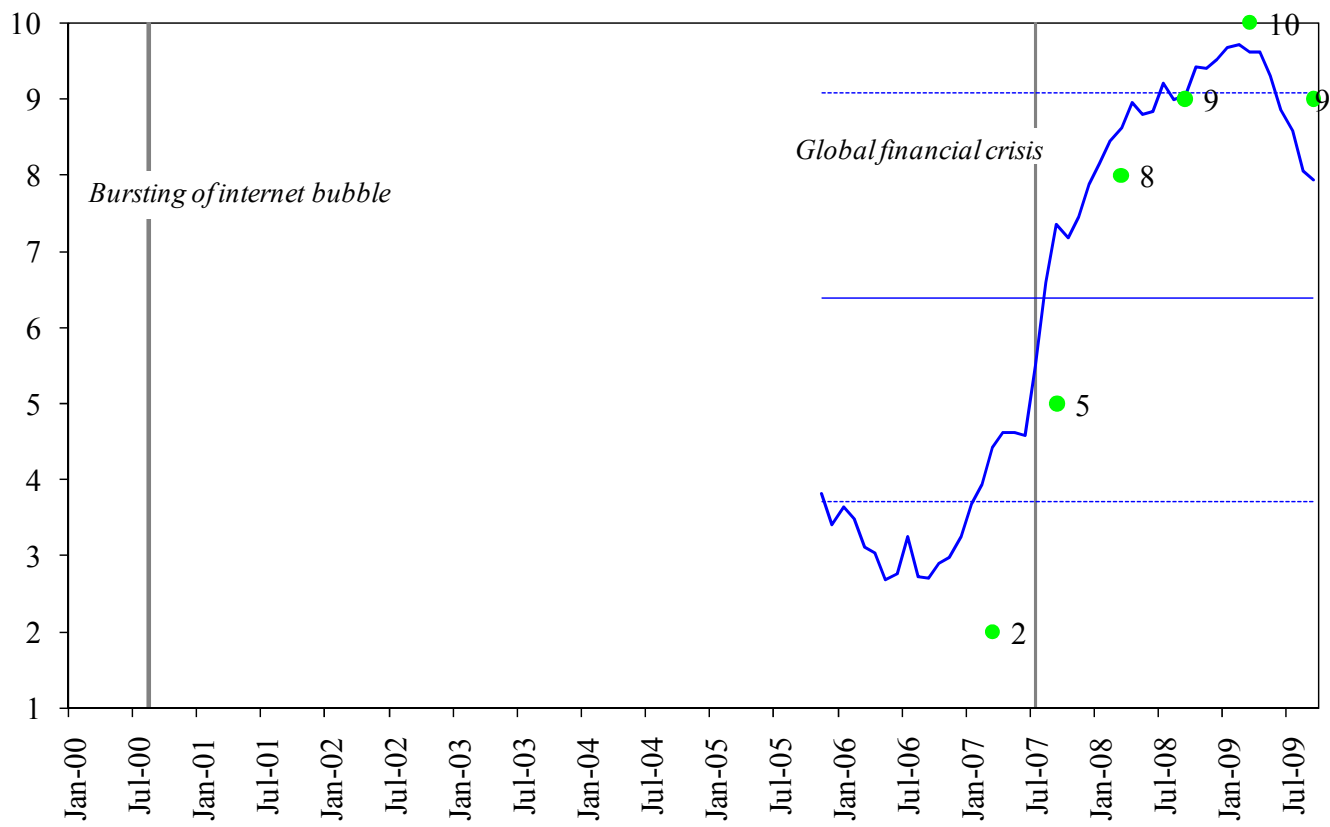

\section{Using subindicators with longer history}

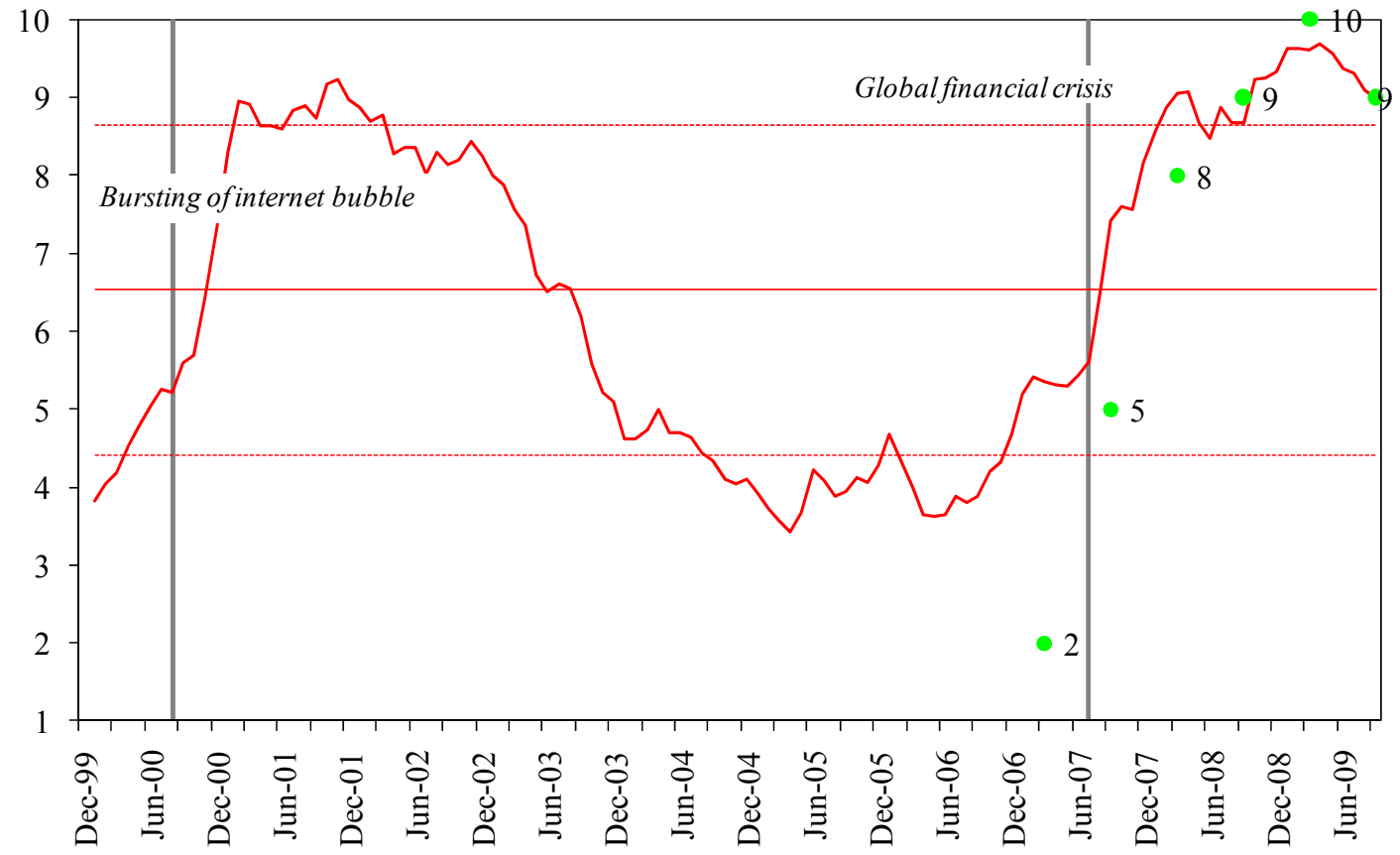

Sources: Bloomberg, Federal Reserve, Merrill Lynch, Moody's, Mortgage Bankers Association, and IMF staff estimates.

Note: The solid lines are the aggregate indices using either a subset of sub-indicators (red) or all subindicators (blue). The dots show the positioning published in past GFSRs (April 2007-October 2009). The solid and broken straight lines indicate the period average and $+/-1$ standard deviation bands. 
Figure 11. Market and Liquidity Risks

(Ranking 0-10)

\section{Using all subindicators}

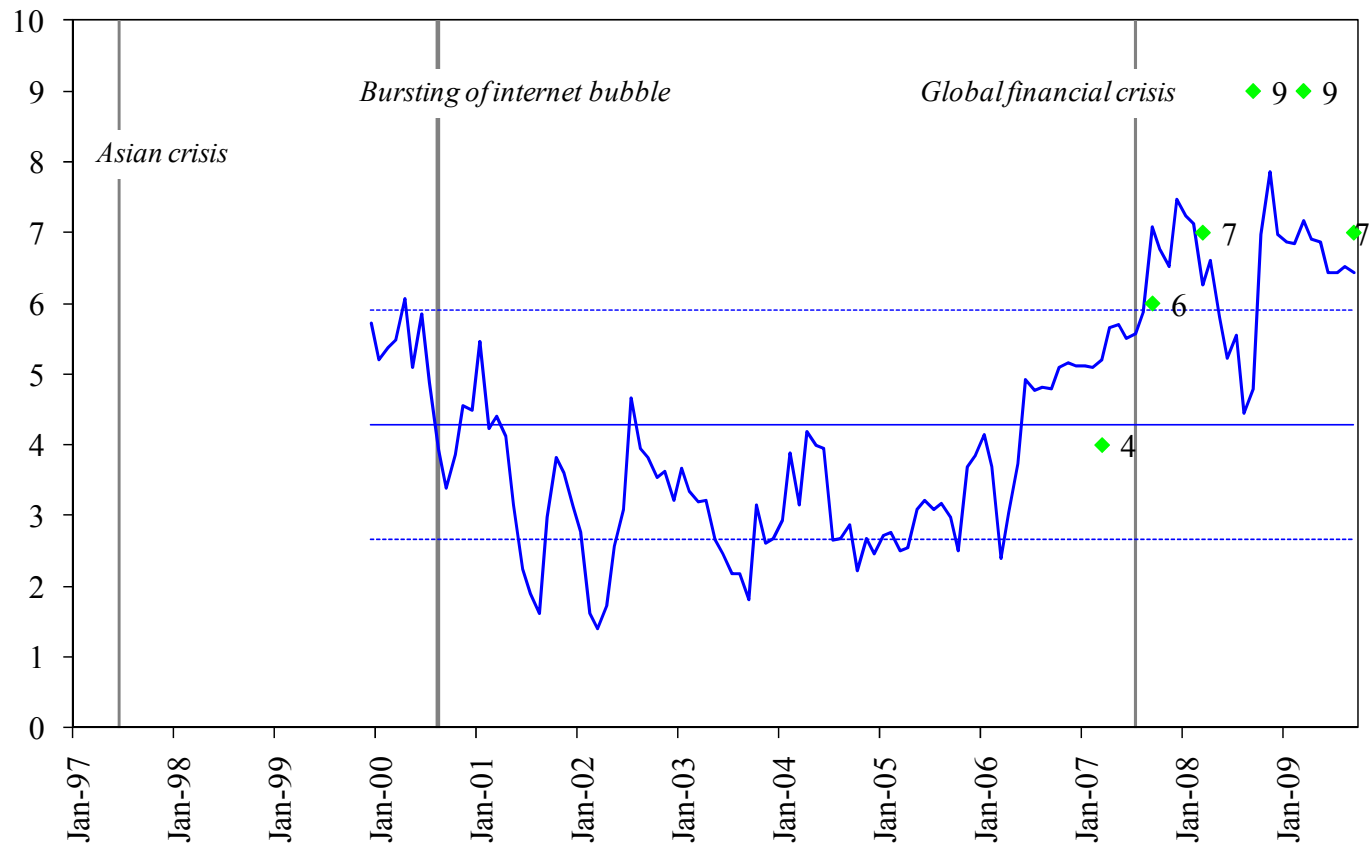

Using subindicators with longer history

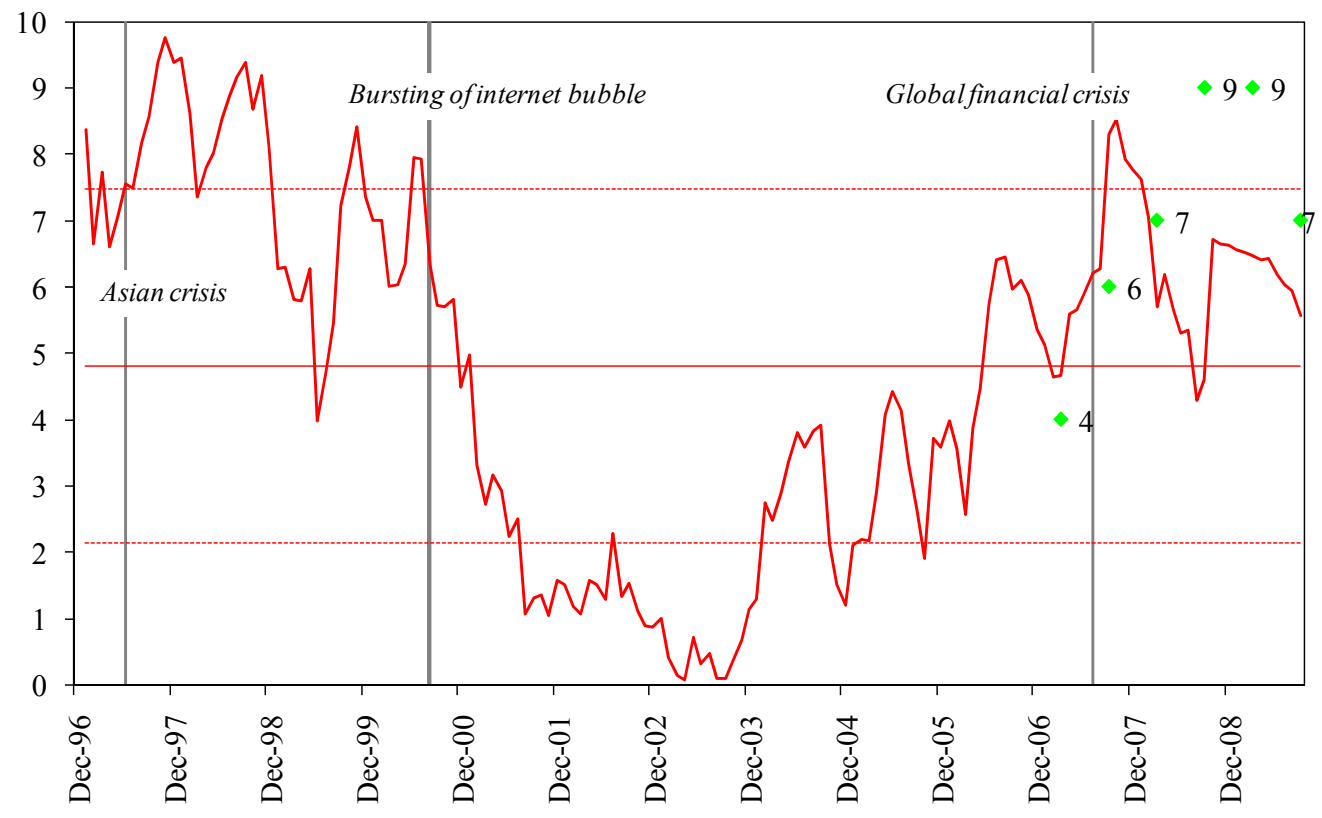

Sources: Bloomberg, Credit Suisse, IBES, JPMorgan \& Chase, Morgan Stanley, and IMF staff estimates. Note: The solid lines are the aggregate indices using either a subset of sub-indicators (red) or all subindicators (blue). The dots show the positioning published in past GFSRs (April 2007-October 2009). The solid and broken straight lines indicate the period average and $+/-1$ standard deviation bands. 


\section{Asian Crisis}

Two of the three indicators signaled a rise in risks months ahead of the onset of the crisis. ${ }^{19}$ Monetary and financial conditions and emerging market risks reached levels outside the one-standard deviation thresholds ahead of the crisis, signaling easy conditions and low perception of risks in emerging markets (Figures 6 and 9). Sub-indicators of market risks also pointed to high leverage and stretched market valuations ahead of the crisis (Figure 11). Macroeconomic risks were close to the threshold signaling a very low perception of risks, but failed to fall outside of the thresholds ahead of the crisis (Figure 8).

\section{Collapse of the U.S. Internet Bubble}

Four of the five indicators in the Map signaled higher stability risks ahead of the stock market crash. Monetary and financial conditions, risk appetite, and credit risks all signaled excessive liquidity and exuberance ahead of the crisis (Figures 6, 7, and 10). Macroeconomic risks rose to high levels well ahead of the crisis (Figure 8). ${ }^{20}$ Some of the sub-indicators under market and liquidity risks, including co-movements in asset returns and equity valuations, also signaled warning signs (Figure 11). The Map did not suggest an escalation in emerging market risks ahead of the crisis, as the crisis was mostly isolated to mature markets (Figure 9).

\section{Summary of Findings}

The model often signaled an intensification in stability risks ahead of the three sampled crisis events. As summarized in Table 1, the Map's performance was fairly consistent across the aggregate indicators of risks and conditions. Most of the indicators signaled rising risks, but with varying lags over time and across indicators. ${ }^{21}$ There was no instance where the model signaled type I or II errors-i.e., false positives and negatives - systematically across many indicators ${ }^{22}$ Also, type II errors for some indicators, such as macroeconomic risks in 1997 and emerging market risks in 2000, can be explained by the more localized nature of the Asian crisis and the bursting of the U.S. internet bubble.

\footnotetext{
${ }^{19}$ Data were available as far back as 1997 only for four of the six risks and conditions in the Map. Risk appetite and credit risk indicators used in the Map were not available at the time of the Asian crisis.

${ }^{20}$ The composition of the sub-indicators of macroeconomic risks is skewed toward mature markets, reflecting their relative size.

${ }^{21}$ While the warning signals preceded the event about 6 months ahead of both the Asian crisis and the bursting of internet bubble, the lags often exceeded one year ahead of the global financial crisis.

${ }^{22}$ For example, low perceived emerging market risks in 2001, high risk appetite in 2003, and excessively easy monetary and financial conditions in 2004 were not followed by crisis events within a 6 to 24 months window.
} 
Sometimes the model's output had to be complemented by judgment and technical adjustment to better characterize the depth of a crisis event. Our assessments of monetary and financial conditions, emerging market risks, and market and liquidity risks were more severe relative to what the model alone suggested at the height of the 2007-9 global credit crisis, highlighting the importance of market intelligence. That said, judgment played a smaller role in determining the final positioning of the Map during normal market conditions.

Table 1. Performance of Map Indicators in Raising Warning Signals Ahead of Selected Crisis Episodes

\begin{tabular}{|c|c|c|c|c|c|}
\hline & $\begin{array}{l}\text { Asian crisis } \\
\text { July } 1997\end{array}$ & $\begin{array}{c}\text { Burs ting of U.S. } \\
\text { internet bubble } \\
\text { August } 2000\end{array}$ & $\begin{array}{l}\text { Global credit crisis } \\
\text { July } 2007\end{array}$ & Type I error & Type II error \\
\hline Monetary and financial conditions & $\sqrt{ }$ & $\sqrt{ }$ & $V_{-}-$ & n.a. & n.a. \\
\hline Risk appetite & n.a. & $\sqrt{ }$ & $\sqrt{ } *$ & $1999,2001,02,03,06$ & n.a. \\
\hline Macroeconomic risks & $\mathrm{x}$ & $\sqrt{-}$ & $\sqrt{-}$ & n.a. & 1997 \\
\hline Emerging market risks & $\sqrt{ }$ & $\mathrm{x}$ & $\sqrt{-}-$ & 2004 & 2000 \\
\hline Credit risks & n.a. & $\sqrt{ }$ & $\sqrt{-}-$ & n.a. & n.a. \\
\hline Market and liquidity risks & $\ldots$ & $\ldots$ & $\ldots$ & $\ldots$ & $\ldots$ \\
\hline
\end{tabular}

Note: $\sqrt{ }\left(V_{-}, V_{-}--\right)$signifies the indicator signaled a warning sign about 6 months (about one year, and more than one year) ahead of the crisis episode. $V^{*}$ signifies when satis factory performance was dictated by judgment. "x" signifies the indicator did not perform well, and "n.a." data was not available or there were not clear errors. Performance was not measured for market and liquidity risks as the indicator is not suited for the assessment.

Judgment and technical adjustment were sometimes also used in determining the positioning of the Map. This was particularly the case for monetary and financial conditions, risk appetite, and emerging market risks, suggesting further room for improvement in the underlying sub-indicators. Judgment based on market intelligence was used to complement our quantitative indicators in order to better reflect key vulnerabilities. This exercise may over- or under-estimate the contributions of judgment used in earlier iterations, as model results presented here do not precisely match those presented in earlier GFSRs, in part because the composition of the Map changed over time.

\section{Conclusions and Further Research}

This paper provides the motivation, methodology, and assessment of a tool developed as part of the IMF's remit to assess and safeguard financial stability. The Map seeks to highlight how various risks and conditions combine to form a specific threat to financial stability. Our initial investigations suggest that the Map performed this objective reasonably well, when applied to prior episodes of instability.

The Map can be usefully extended to different dimensions. It may provide value as a template for central banks and other policymakers, for example by constructing a Map on a national level across a similar set of metrics. The structure may be altered flexibly, by, for instance, introducing additional categories of risks and conditions, or disaggregating certain categories of risk and/or condition that are more important than others to allow for finer assessment. 
Further work will be needed to strengthen the Map's ability to warn against financial stability risk. Additional indicators and techniques will be introduced if they better capture systemic risks. For instance, in light of the importance of leverage and its contribution to financial instability, other measures of leverage are being considered for future iterations. Similarly, the fiscal dimension and of the Map could be bolstered in view of the increased pressure on sovereign balance sheets. Connectivity needs to be strengthened among the different categories of risks and conditions in order to help improve the interpretation of the Map. The number of rays can be enlarged to factor in other sources of risk. For instance, the Map may include infrastructural/operational risk in clearing/settlement and payment systems as well as market microstructure and market institutions (exchanges versus OTC, etc.), since developments in these areas can increase or reduce financial system resilience to a shock. ${ }^{23}$ Judgment remains necessary to some extent, as each crisis is different, and should be informed by financial market intelligence. These factors, however, need to be balanced against the importance of historical comparability as well as model integrity.

Given the degree of judgment and technical adjustment needed to complement the model-determined positioning, there may be further room for improvement in the underlying indicators, especially those comprising monetary and financial conditions, risk appetite, and emerging market risks. As the global credit crisis in 2007-9 underscored, many models were rendered less reliable, as data reached unprecedented values. Similarly, the construction of the Map does not differentiate for these extreme values, which are treated identically. This makes it difficult to precisely monitor the evolution of extraordinary events.

Similarly, more work is needed to assess the reliability of the Map's signals. As more data become available, further research can be done in assessing the Map's performance. In addition, other models and market surveillance tools developed by IMF staff may be incorporated into the Map as they become available.

\footnotetext{
${ }^{23}$ For regulatory treatment of operational risk, see BIS (2001). For the literature on market microstructure, see, for instance, Dattels (1997).
} 


\section{Annex I: Construction and Methodology}

This Annex elaborates on each sub-component underlying the four risks and two conditions of the Map. Table 2 attached at the end of this section lists all the sub-indicators that were either dropped or added during April 2007 GFSR and October 2009 GFSR. Table 3 documents the underlying data and calculation/aggregation methodologies in detail. Figure 12 summarizes the composition of the Map by type of indicators in the October 2009 GFSR.

\section{A. Monetary and Financial Conditions}

The availability and cost of funding linked to global monetary and financial conditions.

\section{(i) G-7 Real Short-Term Interest Rate}

To capture movements in general monetary conditions in mature markets, we begin by examining the cost of short-term liquidity, measured as the GDP-weighted average level of real 3-month Libor rates across the G-7. The central banks of most industrialized countries directly set the cost of borrowing and lending of central bank funds in the interbank marketthe policy rate - and thereby indirectly influence other financial rates in the economy. The cost of liquidity is usually looked at relative to inflation to gauge whether liquidity conditions are accommodative or restrictive.

\section{(ii) G-3 Excess Household and Corporate Liquidity}

This indicator represents a broad measure of excess liquidity, defined as the difference between broad money growth and estimates for money demand. Banks provide money-like liquidity in the form of deposits to the economy as their liabilities. Monetary aggregates, consisting of deposit liabilities of banks plus currency liabilities of the central bank, are therefore a measure of an economy's liquidity. One approach to gauging household and corporate liquidity measures money demand in relation to economic activity. Money demand is estimated from the growth of potential GDP and velocity (the ratio of GDP to broad money over a long horizon). Trend velocity growth is estimated using average velocity growth over a long run in the respective economies, except for the euro area, where it is based on the midvalue of the range for velocity growth as derived by the European Central Bank. The measure for G-3 is converted to a composite indicator using GDP weights.

\section{(iii) Goldman Sachs Global Financial Conditions Index}

The channels through which monetary policy is transmitted to financial markets and to the real economy are complex and no single monetary or interest rate measure has shown a reliable link. For this reason, researchers generally combine these measures with other variables, such as credit spreads, exchange rates, and stock market valuations to more fully capture the effect of financial wealth and liquidity on the economy. The benefits of including broad measures of financial conditions are discussed in English, Tsatsaronis and Zoli (2005). Goldman Sachs produces a representative indicator of financial conditions, which is a 
weighted combination of the real short- and long-term interest rates, real effective exchange rate, and market capitalization of equities in relation to GDP. ${ }^{24}$ We combine such indices for China, the euro area, Japan, and the United States using GDP weights.

\section{(iv) Growth of Custodial Reserve Holdings at the Federal Reserve Bank of New York}

Globalization of finance and trade has brought with it a rise in cross-border ownership of real and financial assets. In particular, increases in public holdings in the form of foreign exchange reserves held by the central bank have an important effect on global liquidity. They create central bank liquidity in the domestic currency to the extent that such liquidity is not sterilized by the central bank. In addition, an accumulation of reserves may contribute to low yields in global fixed income markets, as has been the case in recent years, with the investment of a large share of official reserves into U.S. treasuries and agencies. To measure this, we calculate the annual growth of official international reserves held at the Federal Reserve Bank of New York.

\section{(v) G-3 Bank Lending Conditions}

Changes in lending conditions are an important measure of liquidity creation by the banking sector. Therefore, we look at the results of senior loan officer surveys in the euro area, Japan, and the United States to gauge changes in bank lending attitudes. The underlying series are interpolated on a monthly basis and weighted by GDP to create a composite index. Euro area data from Q1 1991 to Q4 2002 are estimated from credit growth.

\section{B. Risk Appetite ${ }^{25}$}

The willingness of investors to take on additional risk by adjusting exposure to riskier asset classes, the consequent potential for increased losses, and implication for the functioning of broader financial markets

\section{(i) Merrill Lynch Investor Survey of Risk Appetite}

A direct approach to the measurement of risk appetite among global investors is to exploit survey data that explicitly asks major fund managers about their risk-taking investment activity. Since 2001, Merrill Lynch, have conducted a monthly survey of fund managers,

\footnotetext{
${ }^{24}$ The real short-term rates are 3-month Libor, except for China where the 1-year bank lending rate is used. The long-term real rates are proxied by real yields on corporate bonds in the euro area and the United States, and by yields on government bonds in Japan. The FCI for China does not include long-term rates or asset prices. Instead, included in the FCI is an estimated money aggregate derived from the residual of a regression of M2 on real interest rates to capture the effects of credit rationing in a financial system that does not have fully liberalized interest rates.

${ }^{25}$ The green dots in Figure 6 reflect Goldman Sachs Risk Aversion index, except for the dot corresponding to the October 2009 GFSR as the sub-indicator was dropped at that time. The blue and red lines in Figure 6 do not include the sub-indicators.
} 
which covers all major financial centers and currently gets about 200 responses. One question that has been consistently asked since 2001 is "What level of risk are you currently taking in your investment strategy/portfolio, relative to your benchmark?" Possible responses include higher than normal, normal, or lower than normal. Taking the net percentage of those saying higher rather than lower gives a plausible measure of risk appetite. We calculate the 3-month rolling average of the published values. However, the question is asked relative to a benchmark, which may be ill-defined for some investors and change over time.

\section{(ii) State Street Investor Confidence Index}

We infer risk attitudes from actual investment allocation decisions of investors. All else equal, a relative increase in the holdings of riskier asset classes signals an increased willingness to bear risk. A widely followed proprietary index is the State Street Investor Confidence Index. Exploiting their role as custodian for approximately 15 percent of the world's tradable assets, the index uses investors aggregated portfolios to track changes in allocations across asset classes. In practice, the estimated changes in relative risk tolerance of institutional investors from Froot and O'Connell (2003) are aggregated using a moving average. The index is scaled and rebased so that 100 corresponds to the year 2000 . The index rises as allocations increase to riskier asset classes. We use the 3-month rolling average of the published index to guide our assessment.

\section{(iii) Total Net Inflows into Emerging Market Bond and Equity Funds}

Flows into emerging market assets also help to capture investment allocations to traditionally riskier asset classes. In addition, emerging market asset prices are thought to react more strongly than other risk assets to swings in global investor risk appetite which should be reflected in movements in the net flows to emerging market funds. We calculate net inflows into emerging market equity and bond funds using the categorization developed by Emerging Portfolio Fund Research. These flows are scaled by total assets under management to account for the secular upward trend in these flows, and smoothed by taking the 13-week rolling average.

\section{Macroeconomic Risks}

Macroeconomic shocks with the potential to trigger a sharp market correction, given existing conditions in capital markets

\section{(i) Projection of Global Real GDP Growth in the World Economic Outlook}

Our principal assessment of the macroeconomic risks in GFSRs is based on the analysis contained in the IMF's World Economic Outlook (WEO). We measure the extent to which the near-term forecasts of global GDP growth were changed from the previous $W E O$ in percentage ranking, while taking account of risks to the baseline forecast as well. Note that 
when the Map is applied to previous crisis episodes, we do not assess the predictive ability of the $W E O$ 's growth forecasts, due to methodological difficulties. ${ }^{26}$

\section{(ii) G-3 Confidence Indicators}

Economic activity at present is partly dictated by decisions made by economic agents based on their forward-looking expectations. Confidence indicators are survey-based measures that are used commonly to help capture such expectations. We examine a GDP-weighted sum of confidence indices across Germany, Japan, and the United States to determine whether businesses and consumers are optimistic or pessimistic about the economic outlook. The percentile ranking of the observations is determined by difference of current observations from the long run average.

\section{(iii) OECD Composite Leading Indicators}

Recognizing the importance of turning points between expansions and slowdowns of economic activity, we incorporate changes in the Organization for Economic Co-operation and Development's composite leading indicators (OECD CLIs). The selection process of the CLIs' component series considers a wide range of short-term indicators, such as commodity output, business and consumer tendency survey, labor market data, money aggregates, and financial variables, to name a few.

\section{(iv) Implied Global Trade Growth}

Trade has been the key engine of growth for many advanced as well as emerging economies, and its expansion has contributed raise national as well as global wealth. In order to gauge inflection points in global trade, we include global trade growth estimates implied by the Baltic Dry Index (BDI), a high-frequency indicator based on the freight rates of bulk raw materials that is commonly used as a leading indicator for global trade. In practice, the average growth rate of exports and imports are regressed on the BDI for a long horizon, and the coefficients are used to project trade growth using the current BDI data.

\section{(v) Global Breakeven Inflation Rate Index}

A moderate or neutral level of inflation is conducive to economic growth. However, excessively high inflation increases uncertainty around price setting and destroys financial wealth, while disinflation depresses economic activity. In this light, we analyze marketimplied inflation expectations, based on breakeven rates, which are intermediate-dated yield differentials between nominal and inflation-linked domestic bonds. The index tracks GDPweighted longer-term breakevens, or inflation expectations, for Australia, Brazil, Canada, Colombia, France, Germany, Italy, Japan, Korea, Mexico, Poland, South Africa, Sweden, Turkey, the United Kingdom, and the United States. The percentile ranking of the

\footnotetext{
${ }^{26}$ The green dots displayed in Figure 8 corresponding to latest GFSR issues include this sub-indicator, but the blue and red lines do not due to methodological difficulties.
} 
observations is determined by z-score (the deviation from the long run average scaled by standard deviation for the period) in absolute terms.

\section{(vi) Cost of Protection Against Default on Mature Market Sovereign Debt}

The public sector plays an important role to support economic activity through monetary and fiscal policies. In some instances, public sector intervention could become critical to sustain the solvency of private sector institutions. However, costs associated with such measures could impact the health of the public sector. In order to help assess stress levels on sovereign balance sheets, we examine a GDP-weighted average of the cost that investors need to pay to protect against the default by selected mature market sovereigns on their debt.

\section{Emerging Market Risks ${ }^{27}$}

Risks to global financial stability stemming from emerging market asset classes, looking specifically at fundamentals in emerging markets and vulnerabilities to external risks ${ }^{28}$

\section{(i) Estimated Fundamental Emerging Market External Debt Spreads}

Blanchard and Giavazzi (2002) show that as goods and capital markets became more integrated with the rest of the world, countries with prospects for more rapid growth than their trading partners will run larger current account deficits, thus requiring greater external financing. The spread between the yield on the broad JPMorgan EMBIG external debt index and the U.S. treasury yield provides an indication of the financing costs facing emerging market sovereigns in the international debt markets. As economic fundamentals improve and the policy environment becomes more favorable to stability in emerging economies, we would expect the spread to narrow. However, the spread is also likely to narrow when the external environment (e.g., risk appetite) improves. To help isolate the movements in the spread that result from fundamental improvements in emerging economies, we exploit the panel-data model of emerging market spreads presented in IMF (2006). The model allows us to predict the level of the composite EMBIG spread as a result of internal fundamental changes, with external effects removed.

\section{(ii) Emerging Market Sovereign Credit Quality}

Movements in a country's sovereign credit rating on external debt provided a measure of the creditworthiness of the debtor. Credit ratings capture improvements in both the macroeconomic environment facing such economies and progress in reducing vulnerabilities

\footnotetext{
${ }^{27}$ In Figure 9, the green dot corresponding to the April 2009 GFSR reflect an indicator that helped assess an outlook for capital inflows into emerging economies. The sub-indicator was dropped in the October 2009 $G F S R$, and is not reflected in the blue or red line shown in Figure 9.

${ }^{28}$ Emerging market risks are closely linked to, but differ from, the macroeconomic risks, as the latter measures risks related to growth, inflation, or international trade related to the global economy as well as risks to fiscal sustainability in advanced economies.
} 
arising from external financing needs. Since ratings agencies take some time before changing a rating, such moves tend to reflect more permanent changes in a country's outlook than temporary phenomena. The two major ratings agencies, Standard and Poor's and Moody's, have rated the sovereign external debt of most emerging countries for many years. We calculate a rolling sum of ratings upgrades minus downgrades for the emerging market universe. Importantly, we use not only ratings changes but also changes in outlooks and reviews which tend to foreshadow future ratings changes.

\section{(iii) Emerging Market Private Sector Credit Growth}

In addition to the factors relating to sovereign debt, we also include an indicator of growth in private sector credit. We calculate year-on-year growth of domestic credit to the private sector across 44 emerging economies and weight them by GDP. Recognizing that very low credit growth could indicate risks that domestic activity and valuation of local assets may collapse, we calculate z-score of the composite and evaluate the result in absolute terms in order to translate the results to the Map.

\section{(iv) Inflation Volatility}

Higher volatility of inflation is detrimental to macroeconomic stability as it increases uncertainty around expectations of economic activity. We calculate standard deviation of monthly inflation over a one year horizon across 36 countries and take the median value to assess inflation volatility.

\section{(v) Corporate Credit Spreads}

The cost and availability of external financing facing private sector institutions could be very different from those faced by their sovereign. Investors tend to differentiate more according to credit quality when their risk appetite declines, pressuring emerging market corporates. In order to capture financing risks faced by emerging market corporates over and above those faced by the sovereign, we look at the change in the difference between JPMorgan corporate and sovereign external credit spread indices in emerging countries for which both indices are available, and create an unweighted index.

\section{E. Credit Risks}

Credit exposures creating the potential for defaults that could produce losses in systemically important financial institutions as well as the corporate and household sectors

\section{(i) Merrill Lynch Global High Yield Index Spread}

Solvency — and investor perception of it — of private sector corporates is key ingredient of financial stability. The spread on a global high-yield index provides a market price-based measure of investors' assessments of corporate credit risk. We use the widely followed Merrill Lynch index which measures the option-adjusted spread. However, it is important to recognize that prices can deviate from fundamental valuations over an extended period of 
time and tighter spreads may not provide a reliable indicator of potential easing in corporate distress.

\section{(ii) Share of Low-Quality Corporate Debt}

To complement the price measure of credit risks, we also track the quantity of corporate credit that is more likely to become distressed at the aggregate level. We look at the creditquality composition of the high-yield index to identify whether it is increasingly made up of higher- or lower-quality issues, calculating the percentage of the index comprised of CCC or lower rated issues using Merrill Lynch indices.

\section{(iii) Moody's Speculative Grade Default Rate}

Credit quality of the high-yield segment of corporate credit does not remain constant over time. Therefore, in addition to looking at quantity of low-quality corporate credit, we consider projected default rates of such corporates. We do this by incorporating forecasts of the global speculative-grade default rate produced by Moody's.

\section{(iv) Banking Stability Index}

In assessing core financial stability, it is essential to consider the extent of possible contagion of distress from a systemically important bank to the rest of the banking system, along with the viability of such bank independently. Banks are exposed to each other both directly (e.g., interbank markets) and indirectly (e.g., lending to common debtors), and such linkages tend to strengthen in times of stress. Thus, we consider a banking stability index, which represents the expected number of defaults among large complex financial institutions (LCFIs), given at least one LCFI default. ${ }^{29}$ This index is intended to highlight market perceptions of systemic default risk in the financial sector.

\section{(v) Loan Delinquency Rate}

To capture broader credit risks outside of the corporate space, we also include delinquency rates on a wide range of other credit, including residential and commercial mortgages and credit card loans.

\section{(vi) Household Obligation Payment Ratio}

Stress on household balance sheets is measured by the total amount of financial obligations scaled by disposable income for households. ${ }^{30}$

\footnotetext{
${ }^{29}$ Goodhart and Segoviano (2009).

${ }^{30}$ The obligations include estimated payments on outstanding mortgages, consumer debt, auto leases, rental contracts, homeowners' insurance, and property tax.
} 


\section{F. Market and Liquidity Risks}

Market exposures of systemically important financial institutions and the potential for consequent mark-to-market losses, and the extent to which markets may be underpricing risk

\section{(i) Hedge Fund Leverage Proxy}

Hedge Funds accounted for about a third of trading volume in major financial markets prior to the onset of the global credit crisis that started in the summer of 2007, and therefore tend to play a key role as liquidity providers. The stability of financial markets may depend on how well hedge funds manage the use of their leverage, which they employ to amplify the returns to their trading strategies. Such leverage is, however, notoriously difficult to measure. One approach is to measure the sensitivity of hedge fund returns to various asset classes. Changes in a broad hedge fund return index were regressed on returns on major stock, bond and commodity indices. The coefficients on asset returns were summed for each of a sequence of rolling regressions on overlapping 36-month windows (see Box 1.4 of the April 2007 GFSR for more details). There are two major difficulties with this measure. First, as already noted, it is a necessarily indirect measure. Second, estimates are heavily backwardlooking and so will fail to adequately capture recent trends in hedge fund leverage.

\section{(ii) Average Net Speculative Positions in U.S. Futures Markets}

Leveraged investors typically trade actively on futures markets. The potential for disorderly market adjustments is likely to be higher when such investors are heavily skewed either to the long or short side of such markets. The Commodity Futures Trading Commission (CFTC) publishes weekly data on the short and long positions of four categories of traders: (1) producer/merchant/processor/user; (2) swap dealer; (3) managed money; and (4) other reportable on U.S. exchanges. Prior to September 2009, the CFTC used to report the total of (1) and (2) as "commercial", while that of (3) and (4) as "non-commercial". This allows us to, albeit imperfectly, isolate speculative trading activity from hedging and commercial trading. We use data on seventeen futures contracts covering all major asset classes. ${ }^{31} \mathrm{We}$ take a three-month moving average of the average absolute net position of non-commercial traders relative to total open interest across all the contracts. This measure will rise when speculators take relatively large positional bets on futures markets relative to commercial traders, irrespective of direction.

\section{(iii) Estimated Common Component in Asset Class Returns}

Investment portfolios that are well diversified across asset classes would generally be expected to be more beneficial to market stability than heavily concentrated portfolios. However the benefits of such diversification depend on the extent to which asset class returns

\footnotetext{
${ }^{31}$ The futures contracts included are three-month Eurodollars, two, five and ten-year Treasury notes, thirty-year Treasury bond, US dollar index, euro and yen foreign exchange rate, S\&P 500, crude oil, gold, copper, sugar, natural gas, soybeans, corn and wheat.
} 
are correlated. Rising correlations will reduce the stability enhancing effect of such diversification and may result in investors being exposed to more risk than expected. To capture return correlations across a range of risky asset classes, we estimate the proportion of the variation in returns for mature and emerging market equities, external debt and commodities that is explained by the principal common factor over a 90-day rolling window. ${ }^{32}$ Rising correlations across these assets classes should be captured in a rising value for the common factor variation. As with all such factor analysis however, there is only a statistical interpretation to the resulting common factor estimate.

\section{(iv) Equity Risk Premia}

Investors are expected to demand higher returns for holding assets that impose higher chances of making losses. However, when assessed ex-post, it appears that investor perception of the optimal risk-return profile has not always been set appropriately. Excessive risk-taking that is not well justified by the expected rate of return tend to reduce the stability of the financial system. An approach to measure the degree of such risk premia is to estimate equity risk premia in mature markets using a three-stage dividend discount model. Low equity risk premia may suggest that investors are underestimating the risk attached to equity holdings, thereby increasing potential market risks.

\section{(v) Composite Volatility}

Financial market stability is often related to a moderate level of perceived uncertainty. For instance, an excessively low level of perceived uncertainly tends to encourage risk-taking, sometimes leading to a bubble. Asset price volatility is commonly used as a measure of the degree of uncertainty perceived by investors, and volatility implied by option pricing is considered forward-looking. We measure implied volatility across a range of assets, including equity, fixed-income, and currency, and create a composite index after transforming them into z-scores and taking their unweighted average.

\section{(vi) Funding and Market Liquidity Index}

Liquidity in the funding markets ensures stable functioning of the banking system, while liquidity in capital markets helps price discovery and smooth transaction. Funding market liquidity and capital market liquidity are mutually reinforcing, and could become a destabilizing force to the financial markets. To capture perceptions of funding conditions, secondary market liquidity, and counterparty risks, we incorporate into an equally-weighted single index the spread between major mature-market government securities yields and interbank rates, the spread between interbank rates and expected overnight interest rates, bidask spreads on major mature-market currencies, and daily return-to-volume ratios of equity markets. $^{33}$

\footnotetext{
${ }^{32}$ The return indices used are the MSCI World Equity Index, MSCI EM Equity Index, the JPMorgan EMBIG Composite Index and the Goldman Sachs Commodity Index.

${ }^{33}$ See Kerry (2008) for a similar index introduced earlier by the Bank of England.
} 
Table 2. Changes in Indicator Composition Since the April 2007 GFSR

\begin{tabular}{|c|c|c|}
\hline Risk/Condition & Dropped & Added \\
\hline \multicolumn{3}{|c|}{ From April 2007 to October 2007} \\
\hline Emerging market risks & Exchange rate implied volatility & Private sector credit growth \\
\hline \multirow[t]{3}{*}{ Market and liquidity risk } & Value-at-risk of investment banks & Common component of asset returns \\
\hline & & World implied equity risk premia \\
\hline & & Financial market liquidity index \\
\hline \multicolumn{3}{|c|}{ From October 2007 to April 2008} \\
\hline Monetary and financial conditions & & G-3 lending conditions \\
\hline \multirow[t]{2}{*}{ Macroeconomic risks } & & OECD leading indicators \\
\hline & & Implied global trade growth \\
\hline Emerging market risks & & Corporate excess spreads \\
\hline \multirow[t]{2}{*}{ Credit risks } & LCFI portfolio default probability & Banking stability index \\
\hline & & G-3 loan delinquencies \\
\hline \multicolumn{3}{|c|}{ From April 2008 to October 2008} \\
\hline Macroeconomic risks & & Global break-even inflation rates \\
\hline \multicolumn{3}{|c|}{ From October 2008 April 2009} \\
\hline Macroeronomic ricks & & Mature market sovereign credit \\
\hline 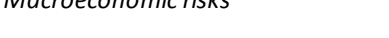 & Economic surprise index & default swap spreads \\
\hline Emerging market risks & & Vulnerabilities to capital flows \\
\hline Credit risks & & Household balance sheet stress \\
\hline \multicolumn{3}{|c|}{ From April 2009 to October 2009} \\
\hline Risk appetite & Risk aversion index & \\
\hline Emerging market risks & Vulnerabilities to capital flows & \\
\hline
\end{tabular}

Sources: GFSRs and IMF staff estimates.

Figure 12. Composition of the Map by Type of Indicators in the October 2009 GFSR (Percent share of total number of indicators)

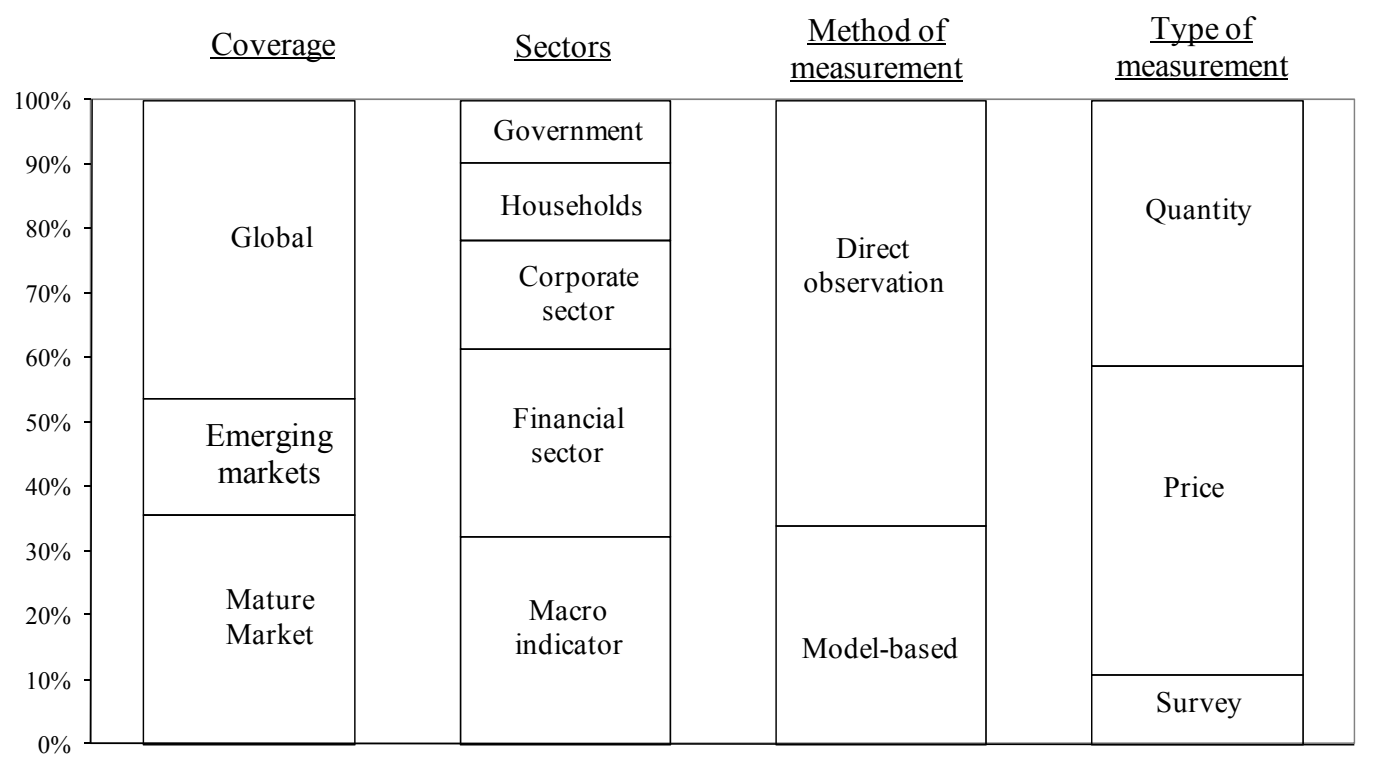

Source: IMF staffestimates. 


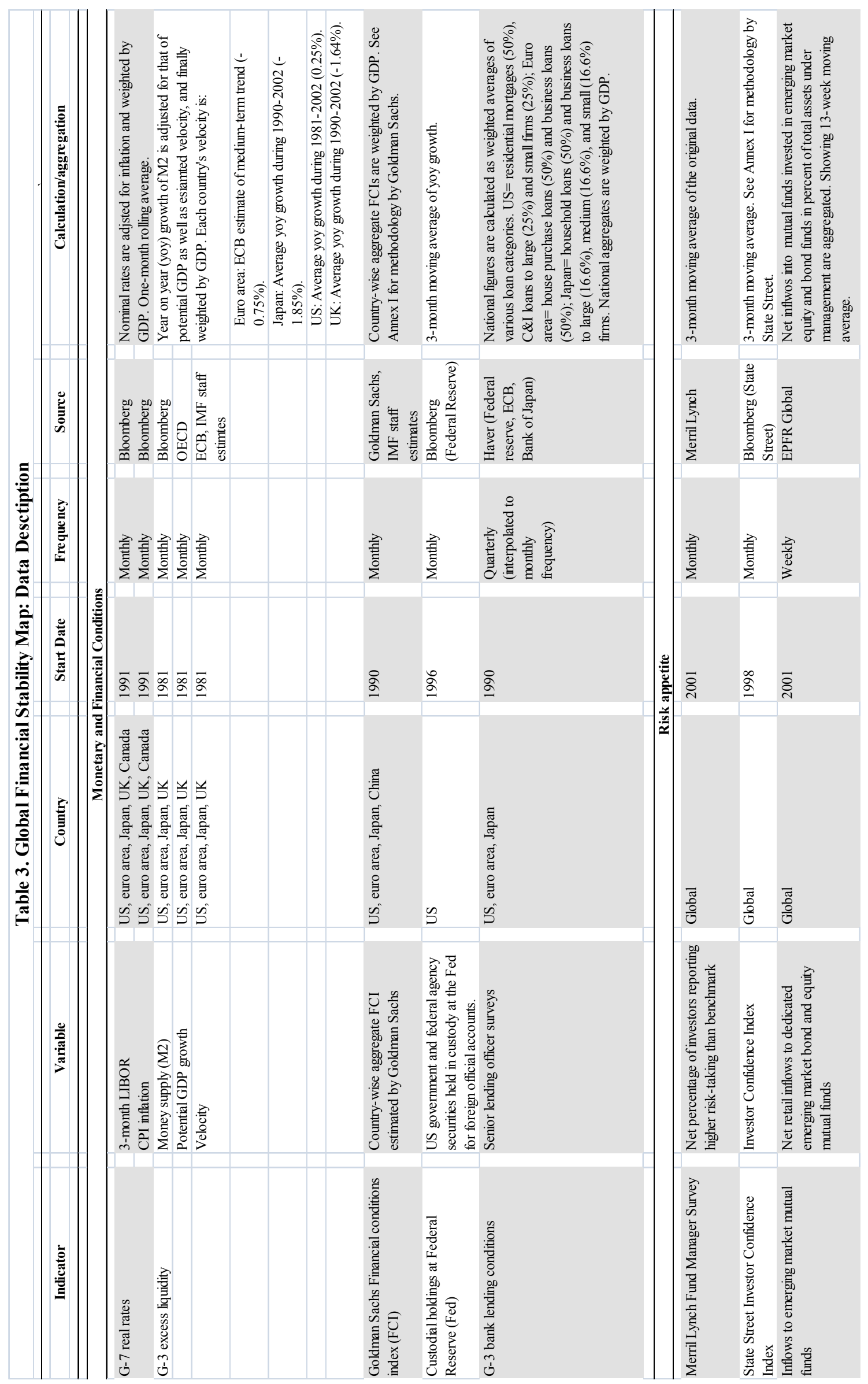




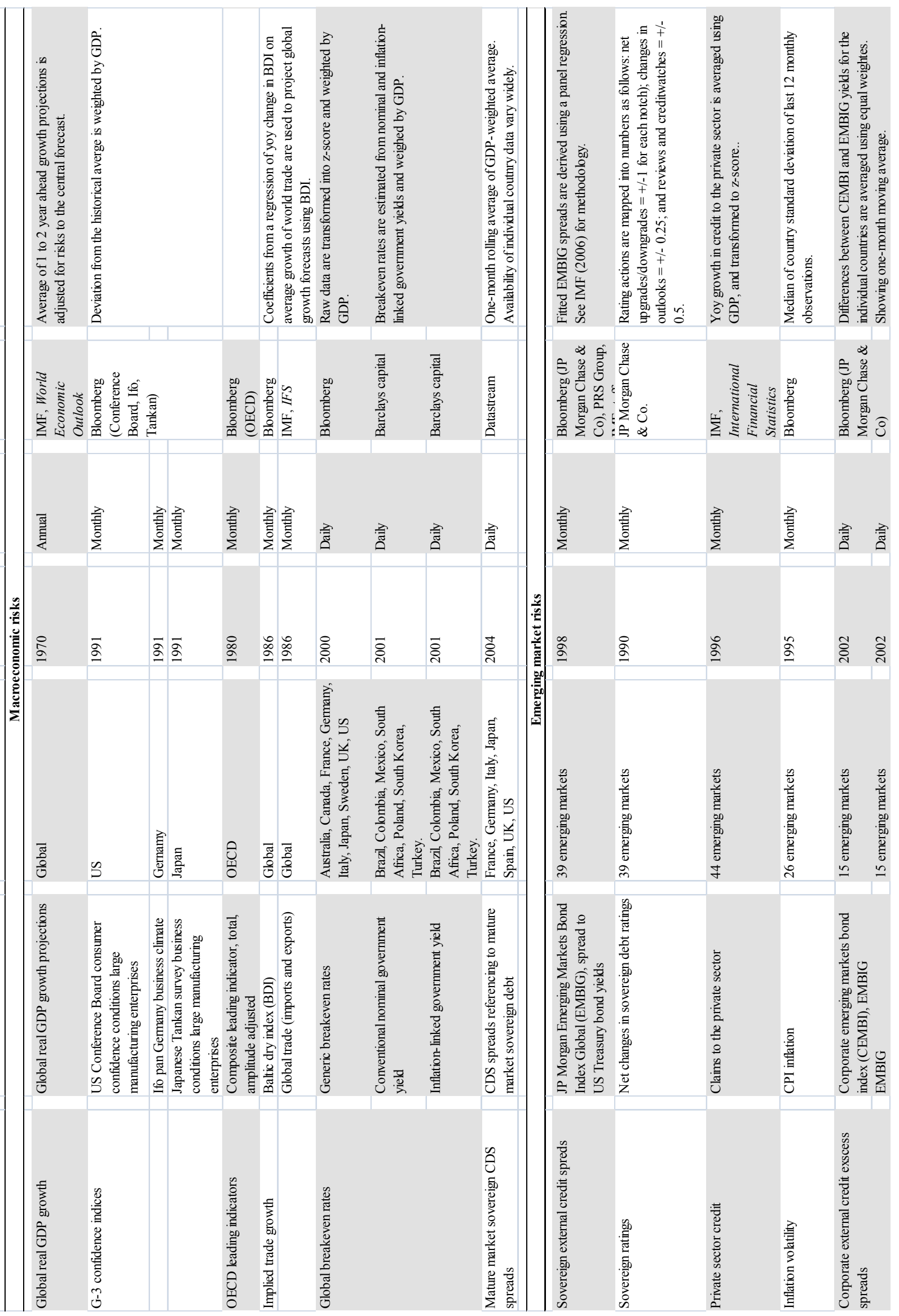




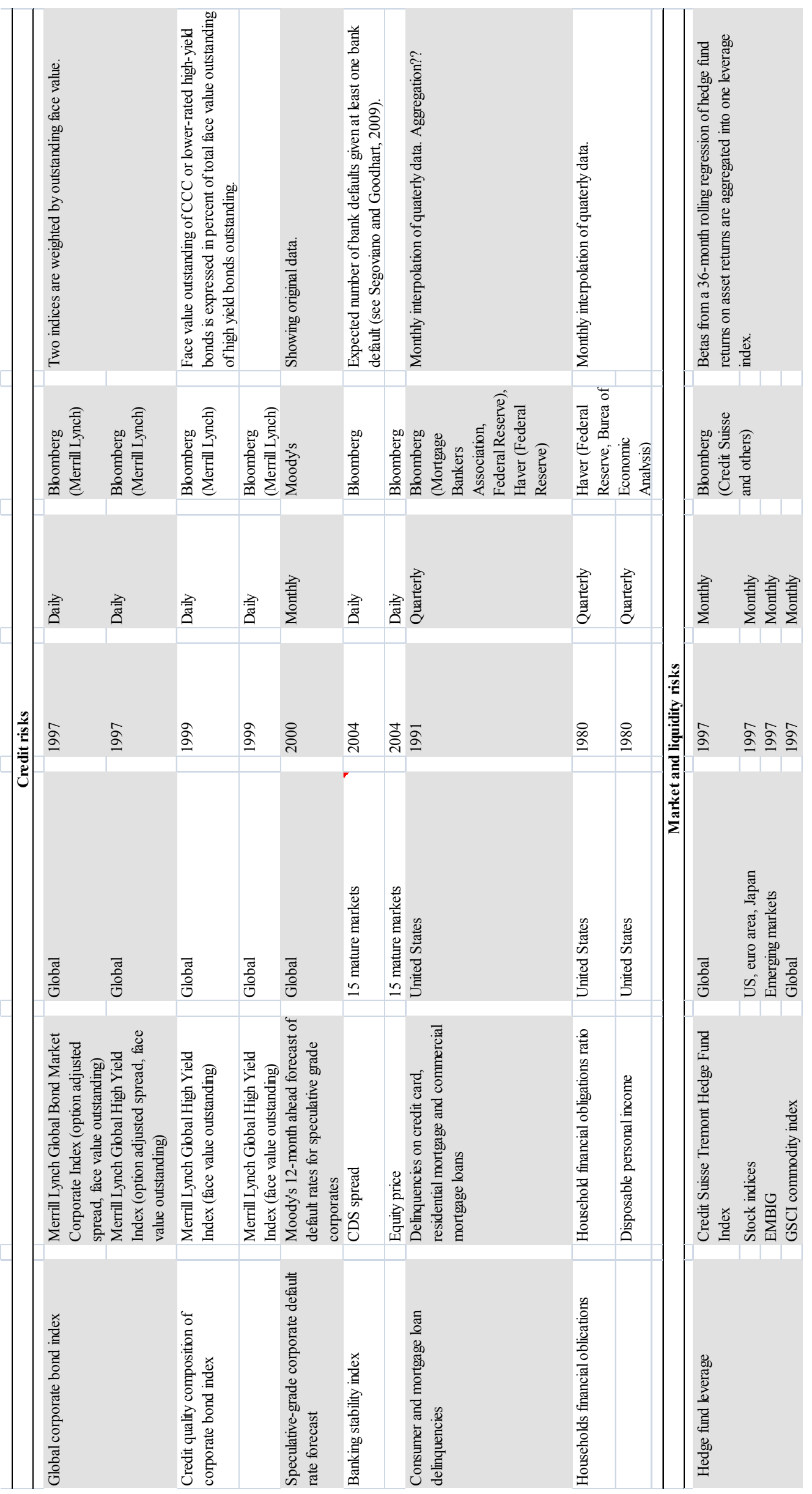




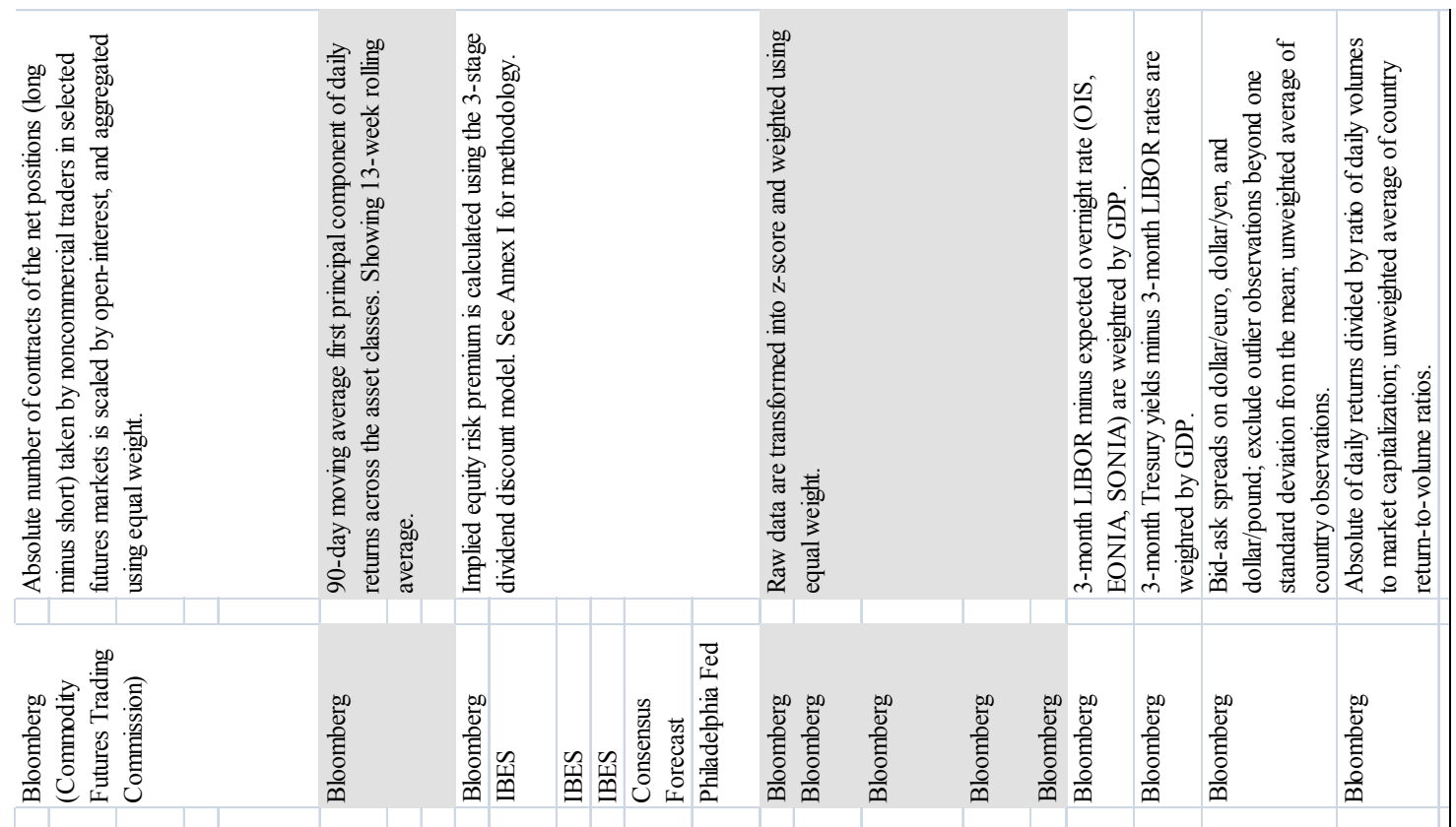

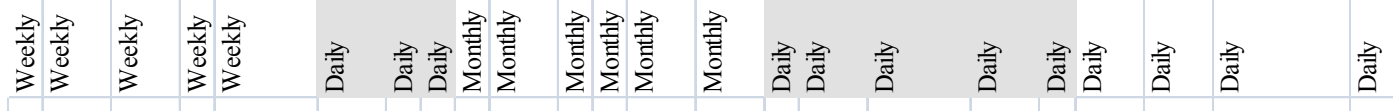

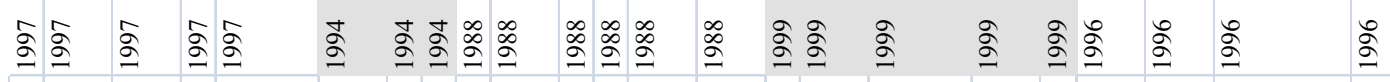

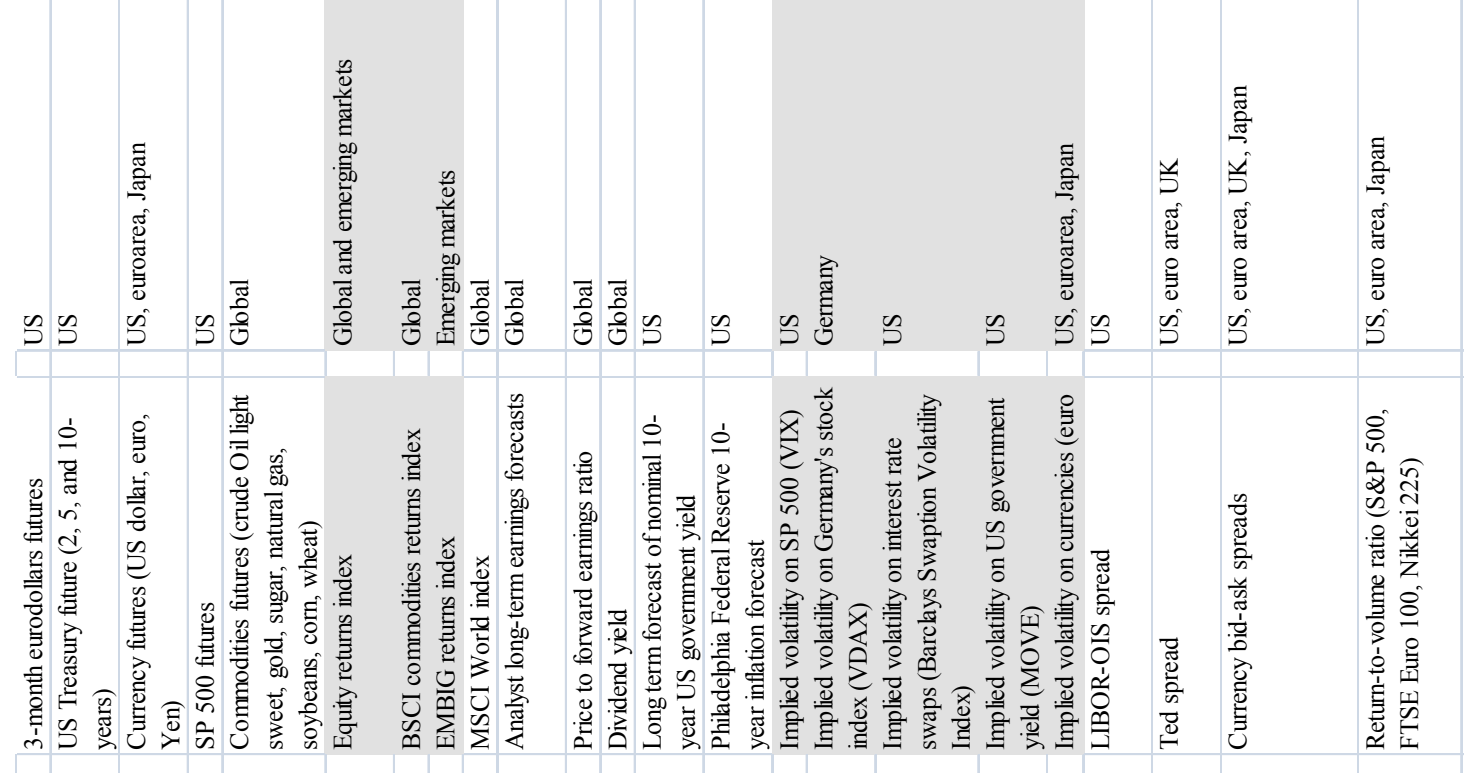

\begin{tabular}{|c|c|c|c|c|}
\hline 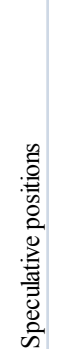 & 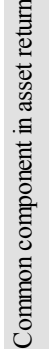 & 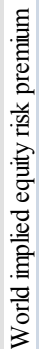 & 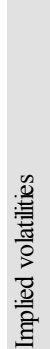 & 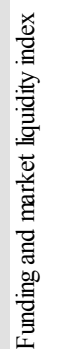 \\
\hline
\end{tabular}




\section{References}

Aspachs, Oriol, Charles Goodhart, Miguel Segoviano, Dimitrios Tsomocos, Lea Zicchino, 2006, "Searching for a Metric for Financial Stability," Financial Markets Group Special Papers SP167.

Bank for International Settlements, 2001, "Working Paper on the Regulatory Treatment of Operational Risk," BCBS Working Papers No.8 (Basel: Bank for International Settlements).

Berg, Andrew, Eduardo Borensztein, and Catherine Pattillo, 2004, “Assessing Early Warning Systems: How Have They Worked in Practice?" IMF Working Paper 04/52 (Washington: International Monetary Fund).

Blanchard, Olivier, and Francesco Giavazzi, 2002, "Current Account Deficits in the Euro Area: The End of the Feldstein-Horioka Puzzle?" Brookings Papers on Economic Activity, Vol. 2002, No. 2, pp. 147-209.

Cihak, Martin, 2006, "How Do Central Banks Write on Financial Stability?” IMF Working Paper 06/163 (Washington: International Monetary Fund).

Dattels, Peter, 1997, "Microstructure of Government Securities Markets," in Coordinating Public Debt and Monetary Management edited by Hans Blommestein, Peter Dattels, and V. Sundararajan (Washington: International Monetary Fund).

Demirgüç-Kunt, Asli and Enrica Detragiache, 2005, "Cross-Country Empirical Studies of Systemic Bank Distress: A Survey,” IMF Working Paper 05/96 (Washington: International Monetary Fund).

English, William, Kostas Tsatsaronis, and Edda Zoli, 2005, "Assessing the Predictive Power of Measures of Financial Conditions for Macroeconomic Variables," BIS Papers No. 22 (Basel: Bank for International Settlements).

Fell, John and Gary Schinasi, 2005, “Assessing Financial Stability: Exploring the Boundaries of Analysis," National Institute Economic Review, Vol. 192, No. 1, 102-117.

Froot, Kenneth, and Paul G.J. O’Connell, 2003, “The Risk Tolerance of International Investors,” NBER Working Paper No. 10157 (Cambridge, Massachusetts: National Bureau of Economic Research).

Gadanecz, Blaise and Kaushik Jayaram, 2009, "Measures of Financial Stability - A Review," IFC Bulletin No. 31 (Basel: Bank for International Settlements).

Goodhart, Charles, and Miguel Segoviano, 2009, “Banking Stability Measures,” IMF Working Paper 09/04 (Washington: International Monetary Fund). 
Hadad, Muliaman, Sugiharso Safuan, Wimboh Santoso, Dwityapoetra S. Besar, Ita Rulina, 2007, Bank Indonesia Financial Stability Review.

Haldane, Andrew, Simon Hall, Silvia Pezzini, 2007, “A New Approach to Assessing Risks to Financial Stability,” Bank of England Financial Stability Paper No. 2.

Hartelius, Kristian, Kenichiro Kashiwase, and Laura Kodres, 2008, "Emerging Market Spread Compression: Is it Real or is it Liquidity?" IMF Working Paper 08/10 (Washington: International Monetary Fund).

Houben, Aerdt, Jan Kakes, Garry Schinasi, 2004, "Toward a Framework for Safeguarding Financial Stability,” IMF Working Paper 04/101 (Washington: International Monetary Fund).

Illing, Mark and Ying Liu, 2003, “An Index of Financial Stress for Canada,” Bank of Canada, Working Paper 2003-14.

International Monetary Fund, Global Financial Stability Report (various issues). , 2008, World Economic Outlook.

Kaminsky, Graciela, Saul Lizondo, and Carmen Reinhart, 1998, “Leading Indicators of Currency Crises,” MPRA Paper No. 6981.

Kerry, Will, 2008, "Measuring Financial Market Liquidity," Journal of Risk Management in Financial Institutions, Vol. 1, No. 2, 181-190.

Oosterloo, De Haan, and Jong-A-Pin, 2007, "Financial Stability Reviews: A First Empirical Analysis," Journal of Financial Stability, 2, 337-355.

Schinasi, Gary, 2004, "Defining Financial Stability,” IMF Working Paper 04/187 (Washington: International Monetary Fund).

Van den End, Jan Willem, 2006, "Indicator and Boundaries of Financial Stability," DNB Working Paper No. 97. 